192

$1 / 5 / 72$
Hh. 2399

ANL/ES-19

\title{
EPISODE CONTROL STRATEGY \\ FOR MOTOR VEHICLES
}

by

A. D. Rossin

\section{ANL}

ARGONNE NATIONAL LABORATORY

CENTER FOR ENVIRONMENTAL STUDIES 


\section{DISCLAIMER}

This report was prepared as an account of work sponsored by an agency of the United States Government. Neither the United States Government nor any agency Thereof, nor any of their employees, makes any warranty, express or implied, or assumes any legal liability or responsibility for the accuracy, completeness, or usefulness of any information, apparatus, product, or process disclosed, or represents that its use would not infringe privately owned rights. Reference herein to any specific commercial product, process, or service by trade name, trademark, manufacturer, or otherwise does not necessarily constitute or imply its endorsement, recommendation, or favoring by the United States Government or any agency thereof. The views and opinions of authors expressed herein do not necessarily state or reflect those of the United States Government or any agency thereof. 


\section{DISCLAIMER}

Portions of this document may be illegible in electronic image products. Images are produced from the best available original document. 
The facilities of Argonne National Laboratory are owned by the United States Government. Under the terms of a contract (W-31-109-Eng-38) between the U. S. Atomic Energy Commission, Argonne Universities Association and The University of Chicago, the University employs the staff and operates the Laboratory in accordance with policies and programs formulated, approved and reviewed by the Association.

\section{MEMBERS OF ARGONNE UNIVERSITIES ASSOCIATION}

The University of Arizona Carnegie-Mellon Univer sity

Case Western Reserve University

The University of Chicago

University of Cincinnati

Illinois Institute of Technology

University of Illinois

Indiana University

Iowa State University

The University of Iowa
Kansas State University The University of Kansas Loyola University Marquette University Michigan State University The University of Michigan University of Minnesota University of Missouri Northwestern University University of Notre Dame
The Ohio State University

Ohio University

The Pennsylvania State University

Purdue University

Saint Louis University

Southern Illinois University

The University of Texas at Austin

Washington University

Wayne State University

The University of Wisconsin

\section{NOTICE}

This report was prepared as an account of work sponsored by the United States Government. Neither the United States nor the United States Atomic Energy Commission, nor any of their employees, nor any of their contractors, subcontractors, or their employees, makes any warranty, express or implied, or assumes any legal liability or responsibility for the accuracy, completeness or usefulness of any information, apparatus, product or process disclosed, or represents that its use would not infringe privately-owned rights.

Printed in the United States of America Available from

National Technical Information Service

U.S. Department of Commerce 5285 Port Royal Road

Springfield, Virginia 22151

Price: Printed Copy $\$ 3.00 ;$ Microfiche $\$ 0.95$ 
ANL/ES-19

ARGONNE NATIONAL LABORATORY

9700 South Cass Avenue

Argonne, Illinois. 60439

\section{EPISODE CONTROL STRATEGY}

FOR MOTOR VEHICLES

by

A. D. Rossin

Center for Environmental Studies

October 1972

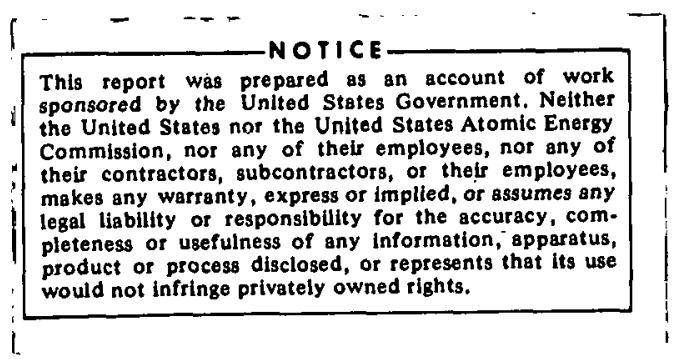

Work sponsored by the

U. S. Environmental Protection Agency, Emergency Operations Control Center, Interagency Agreement No. EPA-IAG-0025(R) 
THIS PAGE

\section{WAS INTENTIONALLY \\ LEFT BLANK}


ABSTRACT. ........................ vi

1.0 Introduction . . . . . . . . . . . . 1

2.0 Pollutant Emissions and Air Quality Problems ........ 5

2.1 Carbon Monoxide . . . . . . . . . . . . 5

2.2 Oxides of Nitrogen. . . . . . . . . . . . . 6

2.3 Photochemical Oxidants. . . . . . . . . . . 11

3.0 Health Effects from Motor Vehicle Pollutants . . . . . . . 13

3.1 Carbon Monoxide . . . . . . . . . . . 16

3.2 Oxides of Nitrogen. . . . . . . . . . . 27

3.3 Photochemical Oxidants. . . . . . . . . . . 28

4.0 Episode Control Strategy . . . . . . . . . . . 30

4.1 Strategy Design . . . . . . . . . . . 30

4.2 WATCH .......................... 31

4.3 ALERT . . . . . . . . . . . . . . . 34

4.4 EMERGENCY . . . . . . . . . . . . . . 37

4.5 CITIZEN ALERT . . . . . . . . . . . . . . . 4 41

4.6 Timing of Alert Declarations. . . . . . . . . . 44

5.0 Criteria for Alert Stages. . . . . . . . . . . 47

6.0 Communications .................. 53

6.1 Communications Plan .................. 53

6.2 Communications Manual . . . . . . . . . . . . 55

6.3 Public Information and Public Understanding . . . . . 63

6.4 Sample Press Releases . . . . . . . . . . 65

ACKNOWLEDGMENTS ............................. 75

REFERENCES. .............................. 76 


\section{LIST OF FIGURES}

No.

1. Carbon Monoxide Emissions by Source Category for Various U.S. Metropolitan Areas in 1968

2. Hourly Average Carbon Monoxide Concentration and Traffic Count in Midtown Manhattan . . . . . . . . . . . 8

3. Average Values of Percent Carboxyhemoglobin in Seven. Nonsmokers. Exposed to $35 \mathrm{mg} / \mathrm{m}^{3}(30 \mathrm{ppm}) \mathrm{CO}$. . . . . . . . . .

4. Concentration and Duration of Continuous CO Exposure Required to Produce Blood $\mathrm{COHb}$ Concentrations of $1.25,2.0,2.5,5.0$, 7.5 , and 10 percent in Healthy Male Subjects Engaging in Sedentary Activity . . . . . . . . . 20

5. Timing of Alerts ............... 45

\section{LIST OF TABLES}

No.

Title

Page

1. National Ambient Air Quality Standards ............ 14

2. Pollution Levels Related to Significant Harm . . . . . . . 15

3. Effects of Carbon Monoxide . . . . . . . . . . . . . 23

4. Ambient $\mathrm{CO}$ Levels Resulting in $5 \% \mathrm{COHb} . . . . . . . . .2626$ 
No.

4.1. Flow sheet for Mobile Source Episode Control. . . . . . . . . . 32

4.2. Mobile Source Episode Control Strategy--WATCH . . . . . . . . . 33

4.3. Mobile Source Episode Control Strategy--ALERT . . . . . . . . . 35

4.4. Mobile Source Episode Control Strategy--EMERGENCY . . . . . . . 39

4.5. Mobile Source Episode Control Strategy--CITIZEN ALERT . • . . . 42

5.1. Mobile Source Episode Control--WATCH Criteria . . . . . . . . . 49

5.2. Evaluation for Mobile Source Episode Control--ALERT Criteria for Carbon Monoxide . . . . . . . . . . . . . . 50

5.3. Evaluation for Mobile Source Episode Control--ALERT Criteria for Photochemical Oxidant . . . . . . . . . . . . 51

5.4. Mobile Source Episode Control--EMERGENCY Criteria . . . . . . 52

6.1. Episode Potential Information Sheet : . . . . . . . . . . 58

6.2. WATCH Declaration Sheet . ................ 59

6.3. ALERT Communications Checklist. . . . . . . . . . . . . . 61

6.4. WATCH Sample Press Release. . . . . . . . . . . . . . . 66

6.5. CARBON MONOXIDE ALERT Sample Press Release. . . . . . . . . . 68

6.6. SMOG ALERT Sample Press Release . . . . . . . . . . . . . 70

6.7. EMERGENCY Sample Press Release. . . . . . . . . . . . . . . 72

6.8. CITIZENS' ALERT Sample Press Release. . . . . . . . . . . . . . 73

6.9. ALL CLEAR Sample Press Release. . . . . . . . . . . . . . 74 
EPISODE CONTROL STRATEGY

FOR MOTOR VEHICLES
A. D. Rosisin.

ABSTRACT

An approach is developed for dealing with pollutants from motor vehicles during air pollution episodes. The ALERT strategy depends on cooperation of all people in the affected region to avoid nonessential use of automobiles when called upon to do so. If the episode becomes lengthy and severe, an EMERGENCY is declared, at which point business, industry, and schools are closed, in effect shutting down the activity of the entire community. This eliminates the need for most persons to use autos or trucks.

The' heal th effects related to carbon monoxide, photochemical oxidants and oxides of nitrogen are sumarized briefly and the bases for designing strategies and setting alert criteria are presented. 


\section{$1.0 \quad$ Introduction}

The conditions which cause air pollution episodes also lead to accumulations of carbon monoxide, nitrogen dioxide, hydrocarbons and, in some cases, photochemical oxidants. The major source of these pollutants in most regions is the internal combustion engines in automobiles, trucks, and buses. While stationary sources also emit $\mathrm{CO}, \mathrm{NO}, \mathrm{NO}_{2}$ and hydrocarbons, the quantities emitted by mobile sources must be curtailed if any kind of effective episode control is to be achieved. In practical terms this means that people will have to give up nonessential driving during air pollution episodes.

In this report a strategy is presented for reducing pollution emissions from mobile sources. Only a limited number of strategy options are actually available. Most fall into the general category of voluntary decisions to limit their own driving by individuals themselves. These range from not making the trip, or postponing it, to the use of carpools and public transportation. In an episode the overall strategy becomes the sum of many individual decisions and therefore its success depends on effective communication to the public through radio, television and newspapers.

In an air pollution episode that persists, and in which pollutant concentrations approach levels that could result in significant harm, emergency measures would need to be taken. It might be necessary to prohibit nonessential driving. Enforced restrictions on driving require extensive pre-planning as well as trained enforcement personnel and a vehicle sticker system to identify cars with a valid need to be used during an emergency. However, if the community strategy for an air pollution energency requires widespread closing of offices, businesses and industry, the obvious effect will be to reduce the need for people to drive. This will cut down 
drastically on the number of vehicles on the road and the overall quantities of motor vehicle pollutants emitted.

The strategy outlined in Section 4 involves three stages:

1) WATCH, during which preparatory actions are taken by agencies, governmental authorities, and the media.

2) ALERT, during which voluntary reductions in driving are accomplished by postponing trips, carpooling or use of public transportation instead of private cars.

3) EMERGENCY, during which the normal day-to-day operations of the city (commercial, industrial, governmental, etc.) are drastically curtailed, eliminating the need for the majority of citizens to drive.

The staged approach, as used in episode control plans for curtailing $\mathrm{SO}_{2}$ and particulates, is designed so that the EMERGENCY stage is declared in time to kcep pollutant levels that would result in an imminent and substantial endangerment to health from ever being reached. Actions taken at the ALERT stage should, if successful, prevent EMERGENCY actions from being required. The WATCH involves no public response, but gives time for preparations and announcements. The WATCH is required in some states whenever an Atmospheric Stagnation Advisory (ASA) is announced by the National Weather Service.

The proposed strategies are designed such that a decision and announcement on any given day can be made in time for people to respond the following day. Whenever an alert is announced, of course, people can respond by avoiding further driving for shopping; errands, etc. However, people who have driven to work will need to drive back home. Therefore, really significant reductions in auto use require that people be told of the need in time to make alternate plans for the coming day. 
Historical evidence shows that significant health problems from air pollution episodes result from extended exposure to bad air. As unpleasant as one bad day might be, it is essential that the appropriate episode control actions be taken to minimize health dangers if the episode lasts longer. In most major cities an episode means an accumulation of sulfur oxides and particulates, as well as carbon monoxides, nitrogen oxides and photochemical oxidants. The combined effect of these pollutants may well be more serious than any one by itself. Therefore, if weather conditions cause an episode, and any pollutant reaches levels high enough to trigger the declaration of an ALERT, the episode plan should provide methods at that stage to reduce all types of emissions. Plans should be flexible however, so that responsible officials can determine what actions should be implemented, based on critical review of the conditions.

The material presented in this report is organized to provide a basis for design of motor vehicle episode control programs tailored to the needs of the region. Section 2 is a brief review of the sources and emission patterns of carbon monoxide, oxides of nitrogen, and hydrocarbons. The phenomenon of photochemical oxidant buildup is summarized, although the mechanisms are actually very complex and deserve a much more detailed treatment. The criterial document on oxidants is a much more informative resource for information and references.

Section 3 provides a brief summary of the health effects of the motor vehicle pollutants upon which air quality standards and "inminent and substantial endangerment to health" levels are based. The latter are levels stipulated by the EPA on August 14, 1971. These are levels below which EPA feels that on the basis of existing knowledge, significant harm to the health of persons would not be expected to occur. It is these levels that are "never to be reached." 
The episode control strategies outlined in Section 4 detail steps that can be taken to reduce motor vehicle emissions in the event of an episode: The actions are predicated on the declaration of an episode control stage. This is clearly differentiated from the process of setting quantitative criteria for declaring control stages. The design of criteria, specifically the air quality levels and other considerations involved in the decision, is presented in "Section 5.

In Section 6 there is discussion about communications and samples of press releases are presented that can be used to provide information to the media, and thereby to the public. 
2.0 Pollutant Emissions and Air Quality Problems

Motor vehicle episode control is directed at those pollutants, $\mathrm{CO}, \mathrm{NO}_{2}$, NO, hydrocarbons and photochemical oxidants, the emissions of which are primarily from motor vehicles. There are other sources that emit these pollutants, but as indicated in Sec. 1.0, if regionwide episode problems exist, vehicle emissions will generally have to be reduced if any significant abatement is to occur.

The proportion of emissions between mobile and stationary sources will vary between localities for the different pollutants. Obvious variables will be the type of industry and its concentrations as well as the traffic mix and density. The extent to which oxidants may build up will also depend on sunlight, along with other meteorological conditions.

In the brief sections that follow, the characteristics of the emission sources for these pollutants are summarized. Detailed discussions can be found in the Criterial Documents $(1,2,3,4)$. However, a general picture of emissions is sufficient to illustrate the approach to episode control presented in Sec. 4. Design of a working strategy for a particular metropolitan area would certainly be more acceptable if a good emission inventory were available for stationary and mobile sources, and if a trans-

portation planning data base is on hand, including hourly traffic densities, and routes and capacities of mass transit systems.

\section{$2.1 \quad$ Carbon Monoxide}

It was estimated that in $196863.8 \%$ of the CO emitted in the U. S. came from transportation sources and $59.2 \%$ (practically all of this) came from gasoline-powered vehicles. For all practical purposes, CO emissions in congested urban areas may be assumed to come entirely from the exhaust of cars, trucks and buses. The only exccption might be an incinerator or 
industrial source like a grey iron cupola (almost obsolete), a blast furnace or petroleum processing operation.

Fig. 1, reproduced from Ref. 1, shows that in major cities the overwhelming proportion of $\mathrm{CO}$ generated is from mobile sources. Further evidence is provided from many studies of $\mathrm{CO}$ concentration in the air as a function of the time of day, as typified by Fig. 2. There is a direct correlation between the concentration of $\mathrm{CO}$ and the traffic density.

Because of the development and installation of exhaust pollution control devices on new automobiles there will be a substantial reduction in total $C 0$ emissions from 1970 to 1980. As older autos are junked, the mix of vehicles will grow newer and the emissions per vehicle-mile will go down. Another favorable influence will be the fact that with improved roads and urban highway system planning the average speed of vehicles will rise and traffic jams will be reduced. Since the efficiency of gasoline engines improves at higher speeds, the CO emissions go down. All of these improvements could be counterbalanced by a continuing increase in the number of vehicles on the roads if technological developments fail to deliver and planning is not effective.

In the meantime, in locations where $\mathrm{CO}$ concentrations can occasionally reach undesirable levels, it will be necessary to reengineer traffic systems or resort to some form of episode control. 2.2 Oxides of Nitrogen

The two oxides of nitrogen that are emitted into the environment and exist in observable concentrations are nitric oxide (NO) and nitrogen dioxide $\left(\mathrm{NO}_{2}\right)$. NO combines with oxygen to form $\mathrm{NO}_{2}$. The reaction normally takes place slowly in air, but the rate of oxidation is significant when the NO is concentrated, as in an exhaust stream. This is because with 

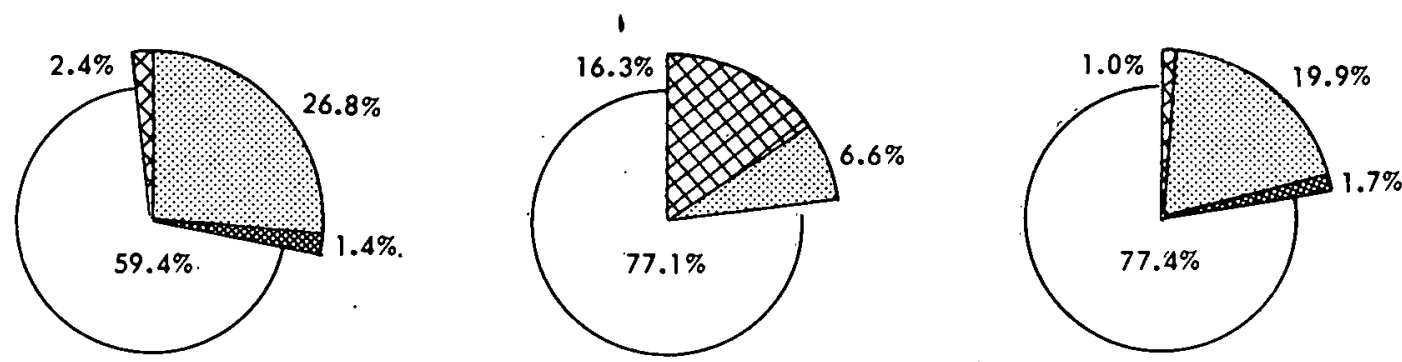

PHILADELPHIA

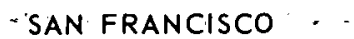

ST. LOUIS
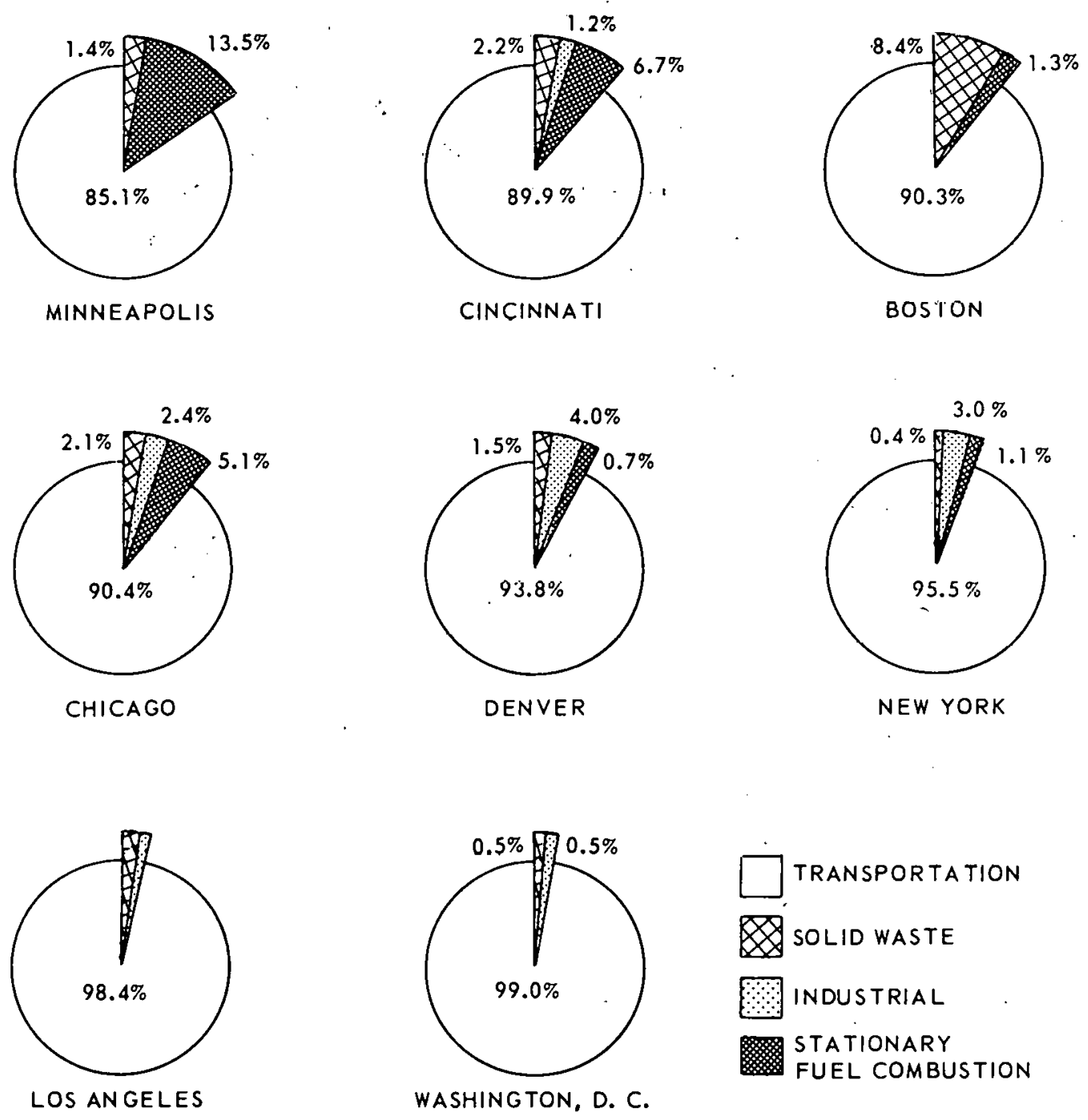

Fig. 1. Carbon Monoxide Emissions by Source Category for Various U.S. Metropolitan Areas in 1968 (Ref. 1, Fig. 4-1). ANL Neg. No. 190-137. 


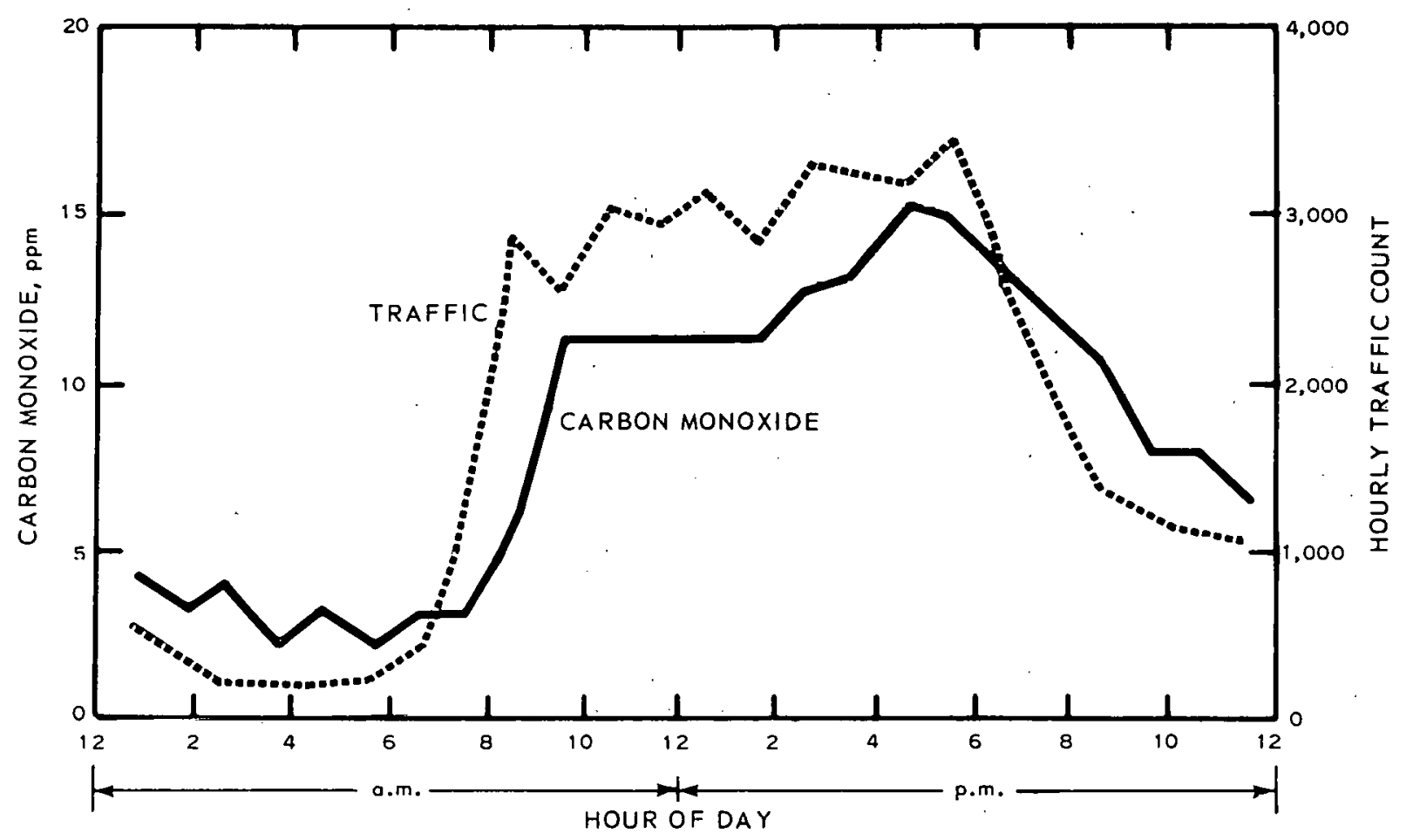

Fig. 2. Hourly Average Carbon Monoxide Concentration and Traffic Count in Midtown Manhattan (Ref. 1, Fig. 6-3). ANL Neg. No. 190-138. 
sufficient oxygen present the reaction rate is proportional to the square of the NO concentration.

NO is also converted into $\mathrm{NO}_{2}$ by a photolytic process with oxygen, $\mathrm{NO}_{2}$, hydrocarbons, and sunlight all involved. The quantitative kinetics of this process are not understood at present.

Another complex set of processes, probably related to the above in some ways, results in the buildup of photochemical oxidants. All of the constituents seem to be necessary to the oxidant production process.

Therefore, in the event of an air pollution episode, in order to prevent further buildup of oxides of nitrogen and oxidants, it is essential that the sources of $\mathrm{NO}$ and $\mathrm{NO}_{2}$ be abated. This means curtailment of fuel burning in power plants and other industrial fuel-burning processes, reduction of emissions from specialized chemical process operations that emit nitrogen oxides (as an example, the TNT plant referred to in the Chattanooga studies [ 5]), and also reduction of emissions from motor vehicles by reducing the number of vehicles on the streets.

Oxides of nitrogen are formed when fuel is burned in the presence of air. The higher the temperature of the process, the greater the likelihood of oxygen reacting with nitrogen, rather than with carbon in the fuel. $\mathrm{NO}_{2}$ appears to be the product of the secondary reaction process suggested above and described in detail in Ref. 2. The primary reaction product is No. The rate of $N O$ production depends on the concentrations of nitrogen and oxygen, the flame temperature, the retention time in the reaction zone, and the rate of cooling. Higher combustion chamber temperatures result in higher rates of NO production.

Thus, more efficient burning from the power output standpoint generally results in higher yields of NO. In the cylinders of gasoline engines 
the combustion conditions are such that nitrogen oxides are produced, the result being that in urban areas, vehicle emissions cause the majority of the man-made nitrogen oxides in the air.

Because power plants generally have high stacks, the ground level concentrations of $\mathrm{NO}$ and $\mathrm{NO}_{2}$ are heavily dependent on vehicle traffic patterns. This relationship is documented in Chapter 6 of the criterial document for nitrogen oxides (2). A plot of hourly concentrations on a selected day in Los Angeles shows a high peak of NO at 7 AM. The NO level then dropped rapidly and by $9 \mathrm{AM}$ the $\mathrm{NO}_{2}$ concentration rose to a peak. It drops much more slowly than the NO level. The ozone level peaked at about noon showing the time lag :generally observed in the formation of high levels of photochemical oxidants. Another piece of evidence illustrates that the hourly levels of NO in Chicago, averaged over a two-year period, showed high values during heavy traffic times. On Saturdays and Sundays, especially during the normal morning rush hours, the peaks were substantially lower.

The various studies of observed nitrogen oxide levels in different cities and over different periods of time offer phenomenological evidence that: 1) the levels in cities are often related to traffic density, 2) they reflect meteorological conditions, 3) they illustrate the photochemical conversion of $\mathrm{NO}$ to $\mathrm{NO}_{2}$ and the production of oxidants, depending on concentrations of $\mathrm{NO}_{x}$, hydrocarbons, and the available sunlight, and 4) they indicate the decay of $\mathrm{NO}$ and $\mathrm{NO}_{2}$ as subsequent species are formed in the oxidation and photochemical process.

The most important aspect of the presence of oxides of nitrogen appears to be as precursors of photochemical oxidants. This process and the role of $\mathrm{NO}_{\mathrm{x}}$ and hydrocarbon emissions:from motor vehicles in providing the raw material for oxidant production is summarized briefly in the next section. 


\subsection{Photochemical Oxidants}

The term "oxidant" is used with respect to urban air pollution problems to refer to ozone $\left(\mathrm{O}_{3}\right)$ or peroxyacetyl nitrates (PAN). Nitrogen dioxide $\left(\mathrm{NO}_{2}\right)$ is also an oxidant, but is generally discussed separately as a pollutant. $\mathrm{NO}_{2}$, however, plays an important role in the production of ozone and PAN.

At the risk of oversimplification of a very complex process that is not quantitatively understood, a brief description of the photochemical oxidant production process follows. For a well-referenced discussion the criterial document on oxidants ( 4 ) is recommended. There is also a significant amount of research and model development in progress, so the current literature on this subject should prove to be an active and steadily growing source of information.

The key photochemical reaction is the breakdown of the $\mathrm{NO}_{2}$ molecule by the ultraviolet energy in sunlight to form NO and a free oxygen atom. Like any free radical, the single oxygen atom is highly active chemically. It will oxidize oxygen $\left(\mathrm{O}_{2}\right)$ molecules to ozone $\left(\mathrm{O}_{3}\right)$ and also can react with a molecule of a hydrocarbon to form a chemically active hydrocarbon free radical. Of the vast number of possible hydrocarbon radicals, some will cause eye irritation and other symptoms, while others will tend to continue the photochemical reaction cycle, cause continued oxidation of $\mathrm{NO}$ to $\mathrm{NO}_{2}$ and continued production of ozone.

The important considerations that bear on control strategy are that automotive exhausts and evaporation can produce hydrocarbons and nitrogen oxides in sufficient quantities so that, if meteorological conditions cause accumulation and sufficient sunlight is present, the production of significant concentrations of oxidants can take place. 
In terms of long-term abatement of photochemical oxidants as urban air pollutants, the EPA is setting strict limitations on the emissions from motor vehicles. The hydrocarbon emission regulation is based on historical data of oxidant levels reached following the presence of high levels of hydrocarbons and $\mathrm{NO}_{\mathrm{x}}$. 'However, before the emission-controlled cars really dominate the scene, and in the event of severe meteorological episode conditions, the only way to reduce emission of hydrocarbons and nitrogen oxides is to reduce the number of vehicles in use. On a short-term basis this can only be done by a well-designed episode control program. 
3.0 Health Effects from Motor Vehicle Pollutants

Research is in progress on the health effects from motor vehicle pollutants. The information available through 1969 is summarized well in the Air Quality Criteria documents $(1,2,3,4)$, which indicate the general nature of the observed health effects. More quantitative data are needed to understand fully the toxicity of these pollutants. However, enough data have been evaluated for the Administrator of the EPA to set ambient air quality standards (Table 1) and levels that might represent an imminent and substantial endangerment to the health of populations (Table 2) Ambient air quality standards are to be met through permanent abatement of emissions. Episode control is designed for short-term application to prevent endangerment of the health.

The levels designated as representing imminent and substantial endangerment to health are not to be reached in the United States. These levels apply to populations and do not guarantee: that no ill effects will befall a single individual even though they are never reached. They do represent levels above which research suggests that statistically there exists an increased potential of significant harm to human health.

The symptoms and the evidence for each pollutant are different; however, for purposes of developing an episode control plan, these designated levels are not to be reached. These levels are given in Table 2. Episode plans must be designed so that all reasonable control actions can be taken to prevent them from being reached. Air pollution EMERGENCY strategy (the last stage of control) should always be put into action below these levels. Earlier stages of control should be initiated to prevent these pollutants from reaching the EMERGENCY levels and also to reduce the irritation or degradation of capability that might result at lower 
Table 1

National Ambient Air Quality Standards (Ref. 6)

\begin{tabular}{|c|c|c|c|c|c|c|}
\hline \multirow[b]{2}{*}{ Pollutant } & \multicolumn{3}{|c|}{ Primary Standard } & \multicolumn{3}{|c|}{ Secondary Standard } \\
\hline & Annual Mean & $\begin{array}{c}\text { Max. Concent } \\
\text { To Be Excee } \\
\text { Than Once }\end{array}$ & $\begin{array}{l}\text { tration Not } \\
\text { eded More } \\
\text { Per Year }\end{array}$ & Annual Mean & $\begin{array}{l}\text { Max. Concentra } \\
\text { To Be Exceede } \\
\text { Than Once Pe }\end{array}$ & $\begin{array}{l}\text { tion Not } \\
\text { d More } \\
\text { r Year }\end{array}$ \\
\hline $\begin{array}{l}\text { Sulfur Dioxide } \\
\left(\mathrm{SO}_{2}\right)\end{array}$ & $\begin{array}{l}80\left(\mu \mathrm{g} / \mathrm{m}^{3}\right) \\
0.03(\mathrm{ppm}) \\
\text { (arithmetic) }\end{array}$ & $\begin{array}{l}365\left(\mathrm{\mu g} / \mathrm{m}^{3}\right) \\
0.14(\mathrm{ppm})\end{array}$ & $24 \mathrm{hr}$ & $\begin{array}{l}60\left(\mu \mathrm{g} / \mathrm{m}^{3}\right) \\
0.02(\mathrm{ppm}) \\
\text { (arithmetic) }\end{array}$ & $\begin{array}{l}260\left(\mu \mathrm{g} / \mathrm{m}^{3}\right) \\
0.10(\mathrm{ppm}) \\
1300\left(\mu \mathrm{g} / \mathrm{m}^{3}\right) \\
0.5(\mathrm{ppm})\end{array}$ & $\begin{array}{c}24 \mathrm{hr} \\
3 \mathrm{hr}\end{array}$ \\
\hline $\begin{array}{l}\text { Particulate } \\
\text { Matter }\end{array}$ & $\begin{array}{l}75\left(\mu g / m^{3}\right) \\
\text { (geometric) }\end{array}$ & $260\left(\mu \mathrm{g} / \mathrm{m}^{3}\right)$ & $24 \mathrm{hr}$ & $\begin{array}{l}60\left(\mu \mathrm{g} / \mathrm{m}^{3}\right) \\
\text { (geometric) }\end{array}$ & $150\left(\mu \mathrm{g} / \mathrm{m}^{3}\right)$ & $24 \mathrm{hr}$ \\
\hline $\begin{array}{l}\text { Carbon } \\
\text { Monoxide }\end{array}$ & & $\begin{array}{l}10\left(\mathrm{mg} / \mathrm{m}^{3}\right) \\
9.0(\mathrm{ppm}) \\
40\left(\mathrm{mg} / \mathrm{m}^{3}\right) \\
35.0(\mathrm{ppm})\end{array}$ & $\begin{array}{l}8 \mathrm{hr} \\
1 \mathrm{hr}\end{array}$ & & Sáme as Prima & \\
\hline $\begin{array}{l}\text { Photochemical } \\
\text { Oxidants }\end{array}$ & & $\begin{array}{l}160\left(\mathrm{\mu g} / \mathrm{m}^{3}\right) \\
0.08(\mathrm{ppm})\end{array}$ & $1 \mathrm{hr}$ & & Same as Prima & \\
\hline Hydrocarbons & & $\begin{array}{l}160\left(\mu \mathrm{g} / \mathrm{m}^{3}\right) \\
0.24(\mathrm{ppm})\end{array}$ & $\begin{array}{l}3 \mathrm{hr} \\
(6-9 \mathrm{AM})\end{array}$ & & Same as Prima & \\
\hline $\begin{array}{l}\text { Nitrogen } \\
\text { Dioxide } \\
\left(\mathrm{NO}_{2}\right)\end{array}$ & $\begin{array}{l}100\left(\mathrm{\mu g} / \mathrm{m}^{3}\right) \\
0.05(\mathrm{ppm}) \\
\text { (arithmetic) }\end{array}$ & & & Same as Primary & & \\
\hline
\end{tabular}


Table 2

\section{Pollution Levels Related to Significant Harm*}

For the purpose of preventing air pollution emergency episodes, each plan for a Priority 1 region shall include a contingency plan wich sha11, as a minimum, provide for taking any emission control actions necessary to prevent ambient pollutant concentrations at any location in such region from reaching levels which could cause significant harm to the health of persons, which levels are as follows:

Sulfur dioxide - 2,620 micrograms/cubic meter (1.0 part per million), 24-hour average.

Particulate matter - 1,000 micrograms/cubic meter or $8 \mathrm{COH}$ 's, 24-hour average.

Sulfur dioxide and particulate matter combined - product of sulfur dioxide in micrograms/cubic meter, 24-hour average, and particulate matter in micrograms/cubic meter, 24-hour average, equal to $490 \times 10^{3}$ or product of sulfur dioxide in parts per million, 24-hour average and $\mathrm{COH}^{\prime} \mathrm{s}, 24$-hour average, equal to 1.5 .

Carbon mońoxide:

57.5 milligrams/cubic meter (50 parts per million), 8-hour average.

$86.3 \mathrm{milligrams/cubic} \mathrm{meter} \mathrm{(75} \mathrm{parts} \mathrm{per} \mathrm{million),}$ 4-hour average.

144 milligrams/cubic meter (125 parts per million), 1-hour average.

Photochemical oxidants:

800 micrograms/cubic meter ( 0.4 part per million), 4-hour average.

1,200 micrograms/cubic meter ( 0.6 part per million), 2 -hour average

1,400 micrograms/cubic meter (0.7) part per million), 1-hour average.

Nitrogen dioxide:

3,750 micrograms/cubic meter (2.0 parts per million), 1-hour average.

938 micrograms/cubic meter ( 0.5 part per million), 24-hour average. 
concentrations.

In the sections that follow the short-term health effects of the motor vehicle pollutants are summarized, largely on the basis of the critical documents. They are discussed separately since each pollutant involves a different type of time dependency.

For carbon monoxide, nitrogen dioxide and photochemical oxidants, EPA has set imminent and substantial endangerment levels. Hydrocarbon emissions are not regarded as particularly toxic. Hydrocarbons from auto fuel and exhausts combine with oxides of nitrogen to produce photochemical oxidants. However, no imminent and substantial endangerment levels have been set for hydrocarbons, and no episode control stage criteria are based on hydrocarbon concentrations. Nevertheless, the hydrocarbon emissions are responsible for unpleasant odors, and during an episode people naturally become aware of the odors in the stagnant air about them.

3.1 Carbon Monoxide (CO)

Clinical studies on $\mathrm{CO}$ have proven that the observed effects are temporary. Even the higheșt exposures being received by populations in congested areas or during episodes cause effects like poorer motor response or drowsiness, and barely approach a range where increased heart stress might be observed. Prolonged exposure to very high levels of CO can be fatal, but these levels are not reached in the enviroment. The health effects from CO result from the buildup of carboxyhemoglobin (COHb) in the blood. The buildup and effects of $\mathrm{COHb}$ are discussed below.

3.1.1 Air Quality Standards and Endangerment Levels

The primary and secondary air quality standards for $\mathrm{CO}$ has been set by the Administrator of EPA (Sec. 410.8 of Ref. 6): 
a) $10 \mathrm{mg} / \mathrm{m}^{3}$ - maximm 8 -hour concentration not to be exceeded more than once per year. ( 9 ppm)

b) $40 \mathrm{mg} / \mathrm{m}^{3}$ - maximm 1 -hour concentration not to be exceeded more than once per year. (35 ppm)

These standards were set on the basis that they would result in $2 \% \mathrm{COHb}$ in the blood of the average nonsmoker. This is an attractive long-term goal for clean air. The imminent and substantial endangerment criteria (see Table 2 ) are 50 ppm averaged over 8 hours, 75 ppm over four hours and $125 \mathrm{ppm}$ for one hour. These exposures correspond to approximately $7 \%, 6 \%$, and $4 \% \mathrm{COHb}$, respectively, in the average human system. It is important to recognize that if the one-hour or four-hour conditions were to continue, higher $\mathrm{COHb}$ levels would develop.

CO concentrations are stated in parts per million (ppm). The concentrations in $\mathrm{mg} / \mathrm{m}^{3}$ are included for reference because standards are stated thus. However, health effects from gaseous pollutants, such as $\mathrm{CO}$, are dependent on molecular concentrations.

The molecular weight of the pollutant molecule is not a significant parameter; hence it may be very misleading to compare pollutant contributions based on the weight of pollutants per unit volume of air. The standard conversion factors apply only for air at standard conditions of pressure and temperature, and to obtain accurate concentrations in $\mathrm{mg} / \mathrm{m}^{3}$, correction factors must be used.

However, the important thing is the concentration in the air that people inhale. Therefore ppm remains the most meaningful unit in which to express CO concentrations.

The health effects data collected and discussed in Reference 1 cover a wide range of exposure levels and times. They discuss observed 
effects of CO on human subjects, on smokers as contrasted with nonsmokers, including both laboratory experiments and analysis of epidemiology data, as well as the results of experiments on laboratory animals.

\subsubsection{Carboxyhemoglobin (COHb) in the Blood.}

Heal th effects from $\mathrm{CO}$ are generally discussed in terms of the percent of $\mathrm{COHb}$ in the blood. $\mathrm{CO}$ forms $\mathrm{COHb}$ in a reversible reaction with hemoglobin in the red blood cells. It competes strongly with oxygen to capture the hemoglobins. The rate of $\mathrm{COHb}$ buildup and the equilibrium level are related to the concentration of $\mathrm{CO}$ in the air a person breathes. The higher the $\mathrm{CO}$ level, the faster $\mathrm{COHb}$ builds up; by returning to pure air the person's $\mathrm{COHb}$ level rapidly decreases. The deterioration of response time, drowsiness, and heart symptoms associated with CO exposure seem to be directly related to the $\mathrm{COHb}$ level in the blood. $\mathrm{COHb}$ decreases the oxygen-carrying capacity of the blood, thereby reducing its ability to deliver oxygen to vital tissues.

For any $\mathrm{CO}$ concentration in air, there is an equilibrium $\mathrm{COHb}$ level that would be reached if a person continues to inhale it for a very long time. Figure 3 illustrates the way $\mathrm{COHb}$ builds up in a person's blood when exposed to a constant level of $\mathrm{CO}(8)$. These data are for nonsmokers exposed to $30 \mathrm{ppm}\left(35 \mathrm{mg} / \mathrm{m}^{3}\right)$ of $\mathrm{CO}$.

Equilibrium is approached in about eight hours; half the equi:librium value is reached in a little more than three hours. The COHb level drops off again at a comparable rate in fresh air.

Figure 4 is a graphical approximation for determining the $\mathrm{COHb}$ level resulting from an exposure to a particular concentration of $\mathrm{CO}$ for a given number of hours ( 9 ). These curves match an equation that approximates experimental data. They are useful for estimating $\mathrm{COHb}$ from acute 


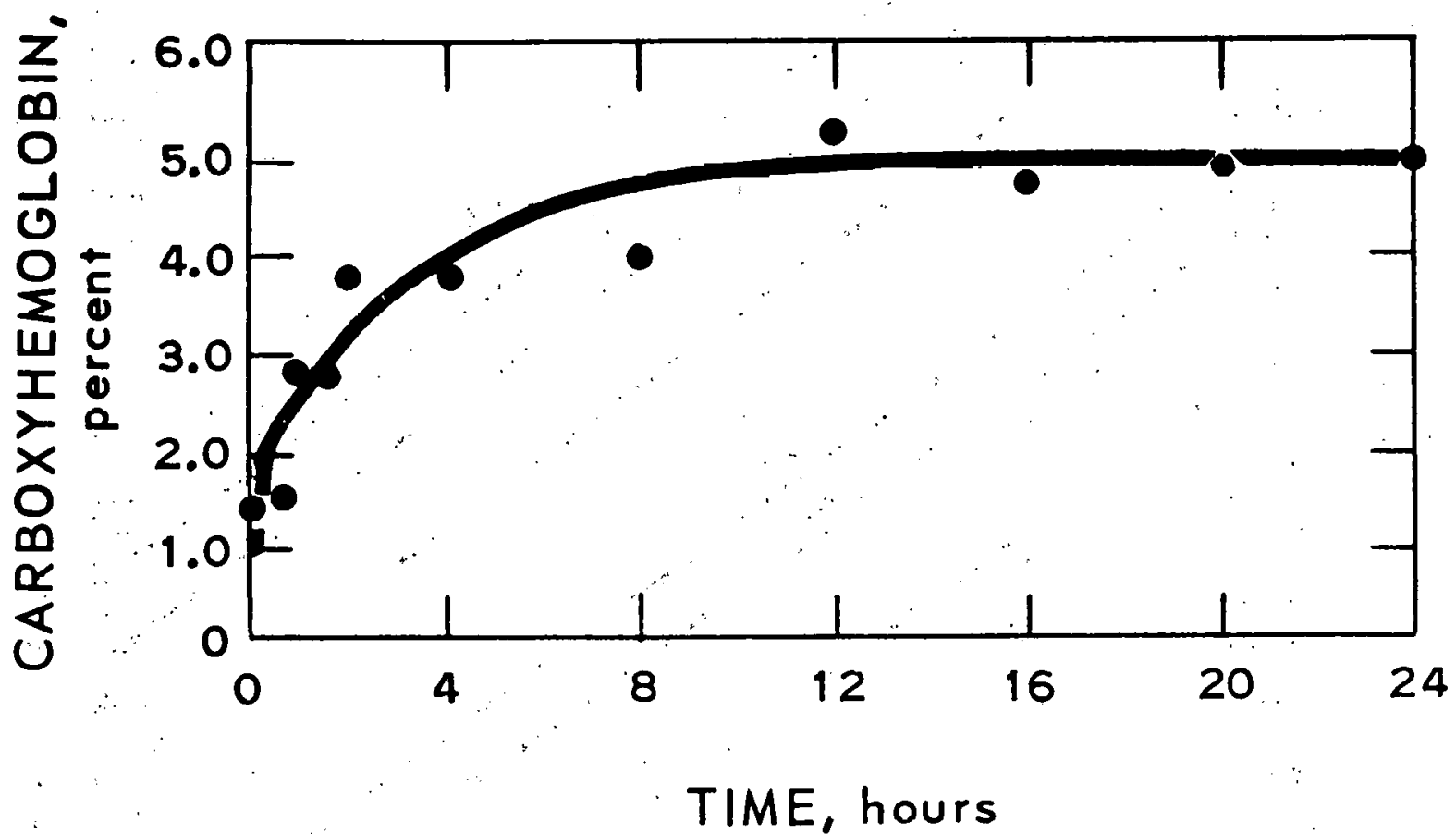

Fig. 3. Áverage Values of Percent Carboxyhemoglobin in Seven Nonsmokers Exposed to $35 \mathrm{mg} / \mathrm{m}^{3}$ (30 ppm) CO 


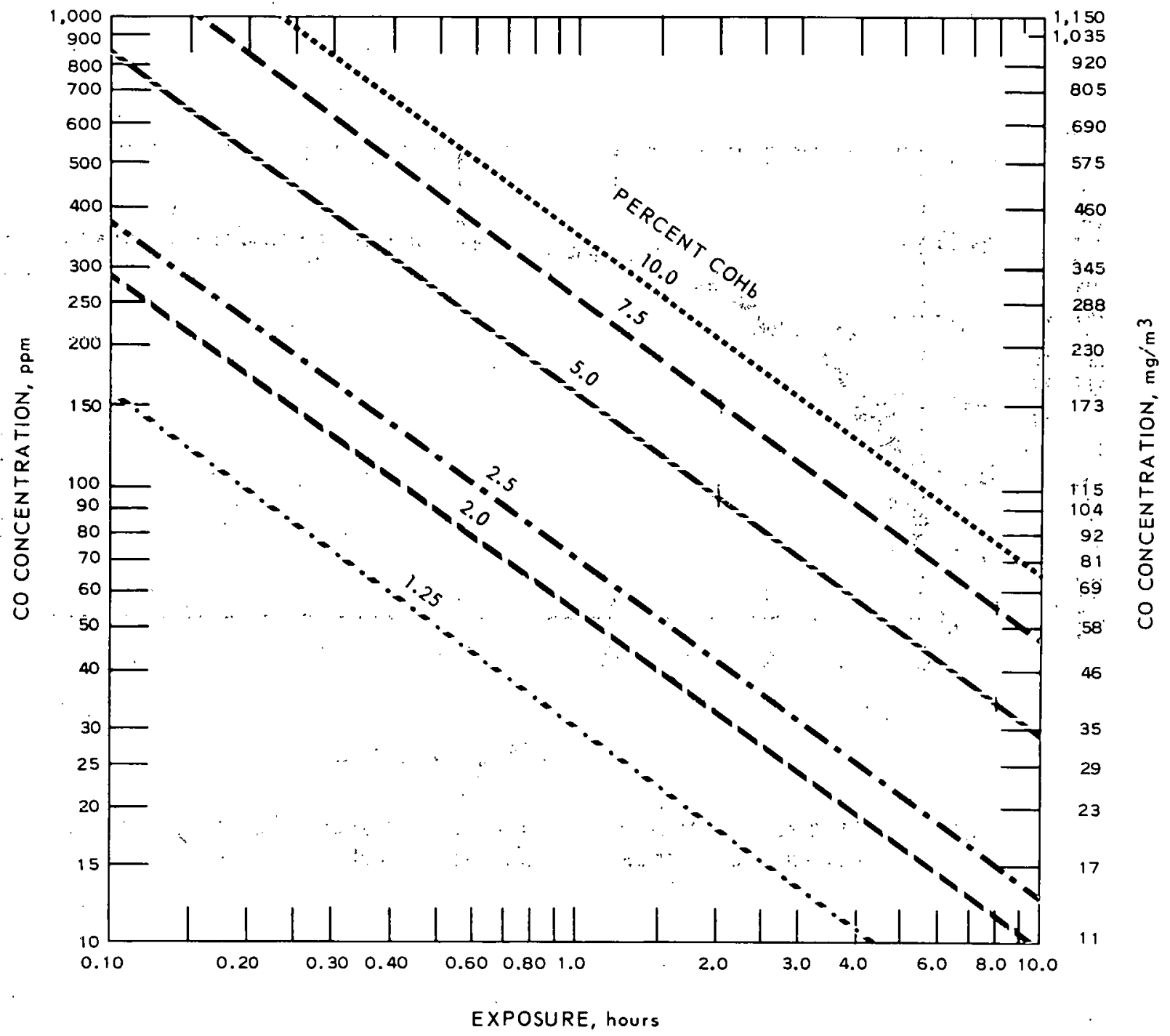

Fig. 4. Concentration and Duration of Continuous CO Exposure Required to Produce Blood $\mathrm{COHb}$ Concentrations of 1.25, 2.0, 2.5, 5.0, 7.5, and 10 percent in Healthy Male Subjects Engaging in Sedentary Activity 
exposures, but do not illustrate the equilibrium behavior clearly for periods longer than 10 hours.

There is a natural background level of $\mathrm{COHb}$ in humans that results from normal metabolic processes. The background level of $\mathrm{COHb}$ in the blood of a typical nonsmoker is 0.4 to $0.5 \%$. A habitual one-pack-a-day smoker may have an average $\mathrm{COHb}$ level of more than $5 \%$ and often exceeds $7 \%$ during portions of the day ( 1 ).

\subsubsection{Physiological and Behavioral Effects of CO Exposure}

The primary standard for $\mathrm{CO}$ was set on the basis of a preventive medicine philosophy. It is a goal that may have to be achieved through substantial modifications in automotive emissions and perhaps changes in urban transportation patterns. The standard is designed to prevent levels of $2 \% \mathrm{COHb}$ from being reached. The $2 \%$ level was chosen because in a series of experiments on time discrimination, the subjects showed impairment of response. It was felt prudent to set a standard at a level that would "contain a sufficient safety margin to provide reasonable certainty that all sensitive groups in the United States will be protected. "The EPA said, "The applicable law in this matter is so clear that no other approach is possible" (10).

The experiment of Beard and Wertheim is the work cited by the EPA in setting the CO standard. Experimental exposure of nonsmokers to $58 \mathrm{mg} / \mathrm{m}^{3}$ (50 ppm) for 90 minutes has been associated with impairment in time-interval discrimination. This exposure will produce an increase of about 2 percent $\mathrm{COHb}$ in the blood. This same increase in blood COHb will occur with continuous exposure to 12 to $17 \mathrm{mg} / \mathrm{m}^{3}$ (10 to $15 \mathrm{ppm}$ ) for 8 or more hours (11). 
The following is quoted from a simmary report compiled by the

National Academy of Sciences: (12)

"Beard and Wertheim have examined the effects of small doses of $\mathrm{CO}$ on the ability of young men and women to judge short intervals of time. The higher the concentration of $\mathrm{CO}$, the greater the number of errors. Measurements were taken over a $2-\mathrm{hr}$. period that began $30 \mathrm{~min}$. after the start of exposure to the gas. Subjects were sealed in a soundproof booth. A 1-sec. tone was presented to the subject; it was followed by a tone that varied in duration between 0.675 and $1.375 \mathrm{sec}$. in steps of $0.125 \mathrm{sec}$. The subject was asked to judge whether the second tone was shorter than, of the same length as, or longer than the first. When the percent of correct responses was plotted against $\mathrm{CO}$ concentration, a linear relationship was found. Because no CO concentrations lower than $50 \mathrm{ppm}$ were used, nothing can be said about a possible threshold effect. Of great potential importance is the fact that the $\mathrm{CO}$ exposure that led to a substantial decrement in correct responses was long enough only to produce a predicted $\mathrm{COHb}$. level of less than $2 \%$. This relationship held in this experiment for exposures from 50 to $250 \mathrm{ppm}$ of $\mathrm{CO}$. If this finding stands upon replication, it will mean that scientists should look much more closely at the effects of $\mathrm{COHb}$ levels that heretofore have been considered of little behavioral significance."

The "substantial decrement" referred to above was an observable drop in correct answers from $80 \%$ to $70 \%$. The significance of this difference in terms of motorist reaction time, for example, is not established. Experimental research on the health effects of $\mathrm{CO}$ is continuing, and the EPA has stated its position that if new and convincing evidence is developed, it will revise its standards, up or down, as called for by the evidence (10). The effects of $\mathrm{CO}$ are summarized in Table 3.

One of the means that may be used to prevent the primary standard from being exceeded after 1975 could be episode control. However, before the 1975 target date for the standards, episode control plans are generally 
Table 3

Effects of Carbon Monoxide *

\begin{tabular}{|c|c|c|c|c|}
\hline \multicolumn{2}{|c|}{ Environmental conditions } & \multirow{2}{*}{$\begin{array}{l}\text { Effect } \\
\text { Equilibrium value of } 5 \text { percent blood } \\
\text { COHb is reached in } 8 \text { to } 12 \text { hours; } \\
80 \text { percent of this equilibrium value, } \\
\text { ( } 4 \text { percent COIIb) is reached wirhin } \\
4 \text { hours. }\end{array}$} & \multirow[b]{2}{*}{$\begin{array}{l}\text { Comment } \\
\text { Experimental exposure of nonsmokers. } \\
\text { Theorctical calculations suggest expo- } \\
\text { sure to } 23(20 \mathrm{ppm}) \text { and } 12 \mathrm{mg} / \mathrm{m}^{3} \\
(10 \mathrm{ppm}) \text { would result in COIb levels } \\
\text { of about } 3.7 \text { and } 2 \text { percent, respec- } \\
\text { tively, if exposure was continuous for } \\
8 \text { or more hours. }\end{array}$} & \multirow{2}{*}{ Referenci: } \\
\hline $\begin{array}{l}35 \mathrm{mg} / \mathrm{m}^{3}(30 \mathrm{ppm}) \\
\quad\end{array}$ & $\begin{array}{l}\text { for up to } 12 \\
\text { hours }\end{array}$ & & & \\
\hline $58 \mathrm{mg} / \mathrm{m}^{3}(50 \mathrm{ppm})$ & for 90 minutes & $\begin{array}{l}\text { Impairment of time-interval discrim- } \\
\text { ination in nonsmokers. }\end{array}$ & $\begin{array}{l}\text { Blood Collb levels not available, but } \\
\text { anticipated to be about } 2.5 \text { percent. } \\
\text { Similar blood COllb levels expected } \\
\text { from cxposure to } 10 \text { to } 17 \mathrm{mg} / \mathrm{m}^{3} \text {. } \\
(10 \mathrm{to} 15 \mathrm{ppm}) \text { for } 8 \text { or morc hours. }\end{array}$ & $\begin{array}{l}\text { Beard and } \\
\text { Wertheitit }\end{array}$ \\
\hline $\begin{array}{l}115 \mathrm{mg} / \mathrm{m}^{3}(100 \mathrm{ppr} \\
\text { through a facial mas }\end{array}$ & mittently & $\begin{array}{l}\text { Impairment in performance of some } \\
\text { psychomotor tests at a COIlb level } \\
\text { of } 5 \text { percent. }\end{array}$ & $\begin{array}{l}\text { Similar results may have becn observed } \\
\text { at lower COHb levels, but blood mea- } \\
\text { surements were not accurato. }\end{array}$ & Schulte \\
\hline $\begin{array}{l}\text { High concentrations } \\
\text { ministered for } 30 \text { to } \\
\text { and then } 10 \text { minute } \\
\text { for washout of alve } \\
\text { blood COHb was m }\end{array}$ & $\begin{array}{l}\text { were ad. } \\
\text { seconds, } \\
\text { allowed } \\
\text { O before } \\
\text { ed. }\end{array}$ & $\begin{array}{l}\text { Exposure sufficient to produce blood } \\
\text { COHb levels above } 5 \text { percent has been } \\
\text { shown to place a physiologic stress on } \\
\text { patients with heart disease. }\end{array}$ & $\begin{array}{l}\text { Data rely on COHb levels produced } \\
\text { rapidly after short exposure to high } \\
\text { levels of } \mathrm{CO} \text {; this is not necessarily } \\
\text { comparable to exposure over a longer } \\
\text { lime period or under equilibrium con- } \\
\text { ditions. }\end{array}$ & Ayres t:t iil. \\
\hline
\end{tabular}

*Reproduced from Ref. 1, Table 10-1. 
being designed to prevent the substantial endangerment to health levels from being reached.

The imminent and substantial endangerment to health exposure levels for $\mathrm{CO}$ are based on values estimated to produce a COHb level of $5 \%$. (Note that this is a typical $\mathrm{COHb}$ level for a regular cigarette smoker.) The 1-hour and 4-hour levels are. set lower, on the reasonable assumption that conditions approaching these levels may persist during hours before and after the criteria are met.

$\mathrm{A} \mathrm{COHb}$ level of $7 \%$ was considered to exceed the maximm to which a significant portion of the population with myocardial illness should be exposed. This finding was based on research that demonstrated that a $5 \%$ $\mathrm{COHb}$ level in some instances showed evidence of impaired performance on some psychomotor tests and impairment of visual discrimination. Above $5 \%$ $\mathrm{COHb}$ there was evidence of physiological stress in patients with heart disease, increased lactate production in patients with coronary heart disease and increased coronary blood flow in patients with noncoronary. heart disease.

Recently available data show that a significant impairment of cardiovascular performance occurs in people with coronary artery disease at levels as low as $3 \% \mathrm{COHb}$. (13) A $5 \% \mathrm{COHb}$ level, therefore, allows no safety 'margin for that segment of the population with cornary artery disease or for subtle but possibly significant decrement in central nervous performance.

Increased physical activity, resulting in greater pulmonary alveolar ventilation, influences the uptake of carbon monoxide. A sitting person takes up ambient CO more slowly than one moving about or engaged in moderate physical activity. Anemia does not influence equilibrium levels 
of $\mathrm{COHb}$ but accelerates the formation of $\mathrm{COHb}$, especially during shortterm exposure to relatively high levels of CO. Table 4 demonstrates ambient $\mathrm{CO}$ levels which will elevate $\mathrm{COHb}$ from $0.5 \%$ to $5.0 \%$ in one hour and three hours of exposure under conditions of no exercise, moderate exercise, and heavy exercise and with normal blood hemoglobin as well as mild anemia.

Exposure to $125 \mathrm{ppm}$ for one hour results in greater than $5 \% \mathrm{COHb}$ in the heavily exercising individual or in a person with moderate anemia engaging in moderate exercise. If one assumes that a one-hour average of 125 ppm may frequently be associated with a three-hour average of $80 \mathrm{ppm}, 5 \% \mathrm{COHb}$ levels will be exceeded in all cases except that of the sedentary individual with normal levels of hemoglobin. The exposure criteria of one hour at $125 \mathrm{ppm} \mathrm{CO}$, in the light of cogent physiologic considerations, does not represent a restrictive standard for preventing substantial endangerment to health.

Thus it is the potential level of $\mathrm{COHb}$ in populations that needs to be controlled: Because of the time-behavior of $\mathrm{COHb}$ buildup, episode control strategy must be designed to take into account both the concentrations of $\mathrm{CO}$ in the air and the time that individuals may be exposed to them. The method of setting $\mathrm{CO}$ alert criteria and the strategy advanced in Section 4 takes these factors into account. 
Table $4:$

AMBIENT CO LEVELS RESULTING IN $5 \%$ COHb*

1 hour 3 hours

Normal Hemoglobin

Sedentary

$200 \quad 80$

Moderate Exercise

130

55

Heavy Exercise

100

50

Moderate Anemia ( $\mathrm{Hb}=10 \quad \mathrm{Gm} \%)$

Sedentary

145

60

Moderate Exercise

90

45

Heavy Exercise

80

40

${ }^{{ }^{*} \operatorname{Ref} .13}$ 


\section{$3.2 \quad$ Oxides of Nitrogen}

As is the case with carbon monoxide, the state of research on health effects from oxides of nitrogen leaves much to be desired. There is perhaps more experimental and epidemiological evidence in the literature than for $\mathrm{CO}$, but the behavior of nitrogen oxides is more complex; controlled experiments are more difficult to perform and analyze. Because nitrogen oxides are precursors of photochemical oxidants, the health effects of the oxidants are closely interrelated.

Nitric oxide (NO) is not an irritant and is not considered to have adverse health effects at concentrations found in the atmosphere. It can be lethal at extremely high concentrations. However, $\mathrm{NO}$ oxidizes to $\mathrm{NO}_{2}$ and thus is a precursor to both $\mathrm{NO}_{2}$ and oxidant buildup. No standards have been sct for NO.

Nitrogen dioxide $\left(\mathrm{NO}_{2}\right)$ can also be lethal at very high concentrations. At levels sometimes observed in the environment, $\mathrm{NO}_{2}$ irritates the lungs and causes breathing difficulties. An epidemiological study of school children in Chattanooga, some of whom were exposed to levels of $\mathrm{NO}_{2}$ $\therefore$ that averaged between 0.06 and 0.10 ppm measured over a 6 -month period ( 5 ), revealed an increassed incidence of acute.bronchitis among those exposed to these levels of $\mathrm{NO}_{2}$. Al though there remains controversy over the methods of measurement and the interpretations of the data from the study (14), the results imply that average concentrations of $0.06 \mathrm{ppm} \mathrm{NO}_{2}$ may be detrimental to health and should be avoided, at least until evidence to the contrary is documented. (10)

Therefore, using the preventive medicine philosophy discussed above, EPA felt obliged to set the primary and secondary air quality stan-

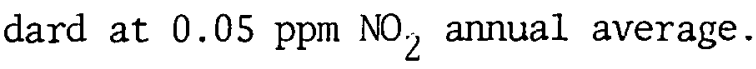


For short-term exposure limits, the EPA reviewed extensive clinical data, both for $\mathrm{NO}_{2}$ and for oxidants, and set levels that reflect the importance of $\mathrm{NO}_{2}$ as a potential contributor to high oxidant levels. The imminant and substantial endangerment criteria for $\mathrm{NO}_{2}$ are $2.0 \mathrm{ppm}$ (3750 $\left.\mu \mathrm{g} / \mathrm{m}^{3}\right)$ 1-hour average and $0.5 \mathrm{ppm}\left(938 \mu \mathrm{g} / \mathrm{m}^{3}\right)$ 24-hour average.

\subsection{Photochemical Oxidants}

The major effects from ozone and photochemical oxidants appear to be short-term rather than from continuing exposure. Eye irritation is the most widely experienced effect, and people notice irritation at a concentration of $0.1 \mathrm{ppm}$. Statistically, if monitors report hourly averages in the range of 0.025 to $0.05 \mathrm{ppm}$, it is likely that peaks of 0.1 would occasionally be detected by a direct continuous reading instrument.

Laboratory studies of human exposure to photochemical smog have involved primarily the measurement of eye irritation. Based on the existing data, it appears that: (1) the effective eye irritants are the products of photochemical reactions; (2) although oxidant concentrations may correlate with the severity of eye irritation, a direct cause-effect relationship has not been demonstrated since ozone, the principal contributor to ambient oxidant levels, is not an eye irritant; (3) the precursors of the eye irritants are organic compounds in combination with oxides of nitrogen, the most potent being aromatic hydrocarbons; (4) the chemical identities of the effective irritants in synthetic systems are known as being formaldehyde, peroxybcnzoyl nitrate (PBzN), peroxyacetyl nitrate (PAN), and acrolein, although the latter two contribute to only a minor extent; and (5) the substances causing eye irritation in the atmosphere have not been completely defined. 
Severe throat irritations was reported at $1 \mathrm{ppm}$, and ozone research indicated increased airway resistance at $0.6 \mathrm{ppm}$.

The criterial document for oxidants (4) also reports aggravation of asthma at 0.05 to $0.06 \mathrm{ppm}$ and impairment of performance by high school athletes who had been exposed to 0.03 to $0.3 \mathrm{ppm}$ the previous hour.

The EPA's primary and secondary air quality standard for photochemical oxidant is short-term only. It is set at $0.08 \mathrm{ppm}\left(160 \mathrm{\mu g} / \mathrm{m}^{3}\right)$ for one hour, not to be exceeded more than one time per year. 'This type of standard, of course, is based on the assumption that air quality data follow a particular log-normal distribution, a situation which may only be accurate for selected locations.

- Ozone has a: characteristic odor and can be detected by most persons at concentrations as low as $0.02 \mathrm{ppm}$. Persons thus become aware of ozone. They can also see the brown photochemical smog, the color and capacity of which is enhanced by the presence of $\mathrm{NO}_{2}$ and humidity. Itching eyes and.irritation of the respiratory tract are also very obvious sensations, by comparison with $\mathrm{CO}$, for example, which is virtually undetectable in environmental concentrations without the aid of instruments.

However, the effects of oxidants, aggravating as they may be, are more of an aggravation and an irritation, rather than a threat to health. For this reason, EPA set endangerment levels for oxidants at the following concentrations and time spans:

$$
\begin{array}{lll}
0.4 \mathrm{ppm} & \left(800 \mathrm{\mu g} / \mathrm{m}^{3}\right) & \text { 4-hour average } \\
0.6 \mathrm{ppm} & \left(1200 \mathrm{\mu g} / \mathrm{m}^{3}\right) & \text { 2-hour average } \\
0.7 \mathrm{ppm} & \left(1400 \mathrm{\mu g} / \mathrm{m}^{3}\right) & \text { 1-hour average }
\end{array}
$$

This set of conditions can thus be taken as those never to be reached for the design of episode control plans. 
4.0 Episode Control Strategy

$4.1 \quad$ Strategy Design

The available strategies for reducing motor vehicle: traffic are really limited to two general types:

1. Voluntary decisions by individuals not to drive, to take public transportation, to carpool, or not to go at all; mearwhile other activities of the community are effectively maintained, except for episode control reductions in emissions by stationary sources that are required to cope with other pollutants.

2. Enforced curtailment, which can only be implemented when normal activities: business, production, education, etc., are substantially curtailed because of an EMERGENCY episode condition. One approach can be to ban all but essential vehicles. These would have to have permits or stickers to allow their use during such a period. Actually, even without specific vehicle ban enforcement provisions, the closing of most establishments will necessarily result in substantial reductions in auto, bus and truck emissions. An EMERGENCY is likely to be a regionwide situation. It is also probable that if meteorological conditions are bad enough to cause one pollutant to reach the EMERGENCY criteria, concentrations of others will be abnormally high, and efforts should be made to abate them.

The proposed approach calls for the voluntary types of actions at the ALERT stage and enforced curtailment in an EMERGENCY. Abatement actions at the EMERGENCY stage involve the virtual shutdown of industrial and commercial activities of the city, thereby removing the need for most traffic. In addition, with a WATCH in effect, the Agency could have the 
option of declaring a CITIZEN ALERT. This is a strictly voluntary appeal to citizens to avoid or postpone any unnecessary driving. The impact may be limited, but it constitutes evidence of control agency action and provides the needed opportunity for citizen involvement. The CITIZEN ALERT can also be declared at any time and implemented at once, in contrast to a regular ALERT, which is really designed to affect traffic for the next day. The basic strategy for a given episode control stage is the same regardless of which pollutant triggers the action by reaching the criteria which have been specified (Section 5). However, the detailed actions to be taken are determined by the control agency, based on conditions. This flexibility is vital to the control official.

The flowsheet for mobile source episode control is presented as Exhibit 4.1. Criteria are evaluated to determine whether an ALERT should be declared or continued. Actions are then implemented, compliance is checked, and the situation reevaluated at the appropriate time.

\subsection{WATCH}

The WATCH (or FORECAST) is a preparatory stage. When a WATCH is declared, the control agencies in the regions covered by the WATCH go on action status. Agencies have standard operating procedures which specify the staff requirements, responsibilities, and actions that are to be taken. A control center is put into operation. This can be a normal part of the agency, but during an episode it is designated as the control center, and it should be fitted out for the activities that will be conducted there.

These activities are outlined in Exhibit 4.1. The statement declaring the WATCH should include the time of declaration, air quality information, the meteorological forecast, and the time of the next scheduled forecast. A sample is given in Section 6. This statement is holpful in 
Exhibit 4.1

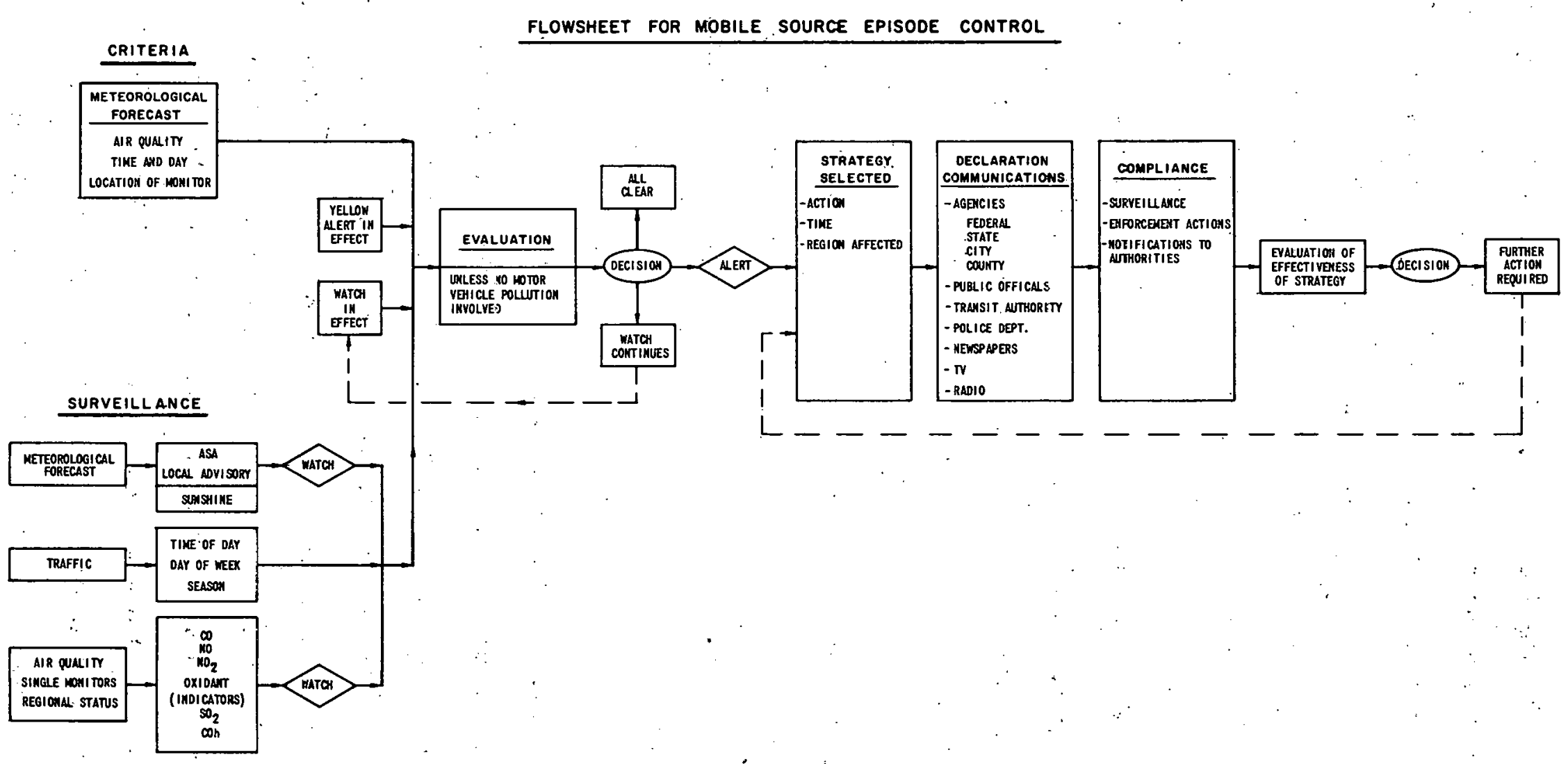


Exhibit 4.2

MOBILE SOURCE EPISODE CONTROL STRATEGY

WATCH

Control Center Activities

Episode Task Force convened

Declaration statement of WATCH and supplementary information posted and prepared for communications

Communications :

Agencies \& Public Officials;

Traffic Police

Media for Pub1ic Announcements

Schools \& Hospitals;

Susceptible individuals

Maintain Surveillance:

Air Quality, Meteorology

Meteorology

Traffic

Traffic helicopter or aircraft for observations

Displays prepared for briefings

Press release prepared and approved

Keep media (and thereby the public) informed

Possible "CITIZEN ALERT" declaration 
phrasing the message given over the telephone to notify agencies, officials, etc.

\section{$4.3 \quad$ ALERT}

This is the action stage through which it is hoped that enough reduction in emissions can be obtained to avoid reaching EMERGENCY criteria. The criteria are discussed in Section 5. If the ALERT criteria are reached, the available information is evaluated. The activities that follow are summarized in Exhibit 4.3. In every way possible, plans should be developed and reviewed in advance. The Communications Manual must be ready for use; police should have been trained in the responsibilities they are to have; press releases should be drafted in advance (see Section 6 for examples) and approved in principle by the responsible authorities.

The ALERT strategy is largely based on voluntary actions, but by means of public announcements, appeals for cooperation, and a broad-based recognition by the community that an air pollution episode is taking place, action becomes acceptable. In fact, if awareness and motivation are adequate, the level of public cooperation could be quite high. People ignoring the appeals for cooperation would receive the upraised eyebrows, rather than those who try to do their part.

Although action is to be voluntary, a successful control strategy will depend on the cooperation of business and industry. This is important if large groups of citizens are to curtail their driving. If they are to inconvenience themselves and complicate their travels to and from work, their employers must accept the need for special action, not penalize employees for trying to cooperate, and indeed, encourage executives and other management personnel to set good examples. 
Exhibit 4.3:

MOBILE SOURCE EPISODE CONTROL STRATEGY

ALERT

Factors to be Considered:

Forecast

AQ levels exceed criteria for ALERT

Day of week

Time of day

Control Center Activities:

Evaluation of available information

ALERT declared for tomorrow

Communications manual followed; all notifications made

Media broadcast declaration so that offices, factories, etc. receive word before 4 PM

Surveillance continued

Displays updated

Strategy:

Appeals to public for immediate elimination of nonessential driving.

Definitely for tomorrow all nonessential driving is to be avoided.

Plan before leaving work:

Do not drive unless necessary;

Carpool to work or use public transportation;

Stagger work hours if feasible;

No unattended idling;

Minimize idling;

Media inform parking lots, parking garage, gas stations;

Medically susceptible persons $\mathrm{OK}$ 'd to take tomorrow off or work at home;

Restrict activity of susceptible persons

Action Plans:

Police: to move traffic as smoothly as possible

State Police: urge thru traffic to bypass

Transit authorily and railruads:

Check capacity available: Constraints, problem spots

Load projections

Buses

Trolleys

Taxis

Fleet Vehicles

Elevated

Subway

Limos 
Exhibit 4.3 - Continued

MOBILE SOURCE EPISODE CONTROL STRATEGY

ALERT

Check manpower: Union rules

Defer maintenance

Media notification:

Predetermine press deadlines

Pre-prepared texts of announcements

Prearranged, taped or live interview 
The managements of firms would be expected to pass ALERT announcements on to employees early enough so that carpools can be planned or work hours can be adjusted.

The stresses on a municipal transit system will be significant. If citizens cooperate by taking public transportation, it will be essential for all available vehicles to be in operation, all ticket booths will need to be manned, and a full staff of operators, drivers, conductors and other operations' personnel will be needed. Scheduled maintenance of vehicles may have to be rescheduled. Detailed action plans have to be prepared in advance, and personnel trained for assignments that will have to be handled if an ALERT is declared.

Many governmental units will also need action plans. Police departments should hold training programs. It is just as important for officers to know what not to do as what to do! For example, a prohibition against leaving engines idling while unattended is an important feature of the strategy. Do police have authority to write nuisance tickets? This depends on local ordinances. If so, how long must the driver be away to constitute "unattended" operation? Can a police officer legally enter a vehicle and shut off an engine? Must he write a ticket? Can automobiles that are badly out of tune and have smoky exhausts be ticketed? Can an arrest be made? Episode regulations will be needed, and then action plans and training programs must be used if the strategy is to be truly effective. 4. 4 EMERGENCY

The EMERGENCY stage requires that every action that can safely be taken to reduce pollutant emissions will be taken. After extensive analysis and discussion, the evidence is clear that there is no good way to reduce driving to any significant extent if normal community activities are 
expected to continue. Therefore the strategy for an air pollution EMERGENCY is to shut down the city to the extent possible without endangering life or causing problems that would prevent return to normal conditions. Implementation of the EMERGENCY strategy is a very serious step for a city to take (see Exhibit 4.4). Economic losses are bound to occur. People lose hours and maybe days of work. Production is suspended and can only be made up at greater cost later. Schedules are thrown back; appointments are missed; people are sure to get angry.

But even more important: in any situation that involves serious disruptions, there are risks that accidents, mishaps, breakdowns, and fai1ures may occur because the normal way of life is changed. It will be human nature, if a person suffers an injury, to blame it on the strategy rather than the episode.

There are two serious problem areas:

1. People will be critical of control officials and elected or appointed local, state, and even Federal officials for any problems, losses or accidental deaths that might occur during the EMERGENCY stage. There are bound to be critics, whether a good job has been done or not. Therefore, officials need clear criteria and procedures for declaring an EMERGENCY. These procedures must be followed carefully. Next, the citizens must be kept informed as fully as possible. This requires pre-developed information packages and, even better, in episode-prone areas, a public information program that informs people about what episodes mean, what the control plans are, what people will have to do to comply, and what effect people's actions might have on air quality. People will have to cooperate in an EMERGENCY, and therefore public information is crucial.

2. There is great danger of confusion on the part of citizens 
Exhibit 4.4

MOBILE SOURCE EPISODE CONTROL STRATEGY

EMERGENCY

Regional Air Pollution EMERGENCY declared

Control Center Activities:

Evaluation and surveillance;

Continuing consultation with-Governor, Mayor, County Board, EPA, EOCC.

Communications:

Regionwide announcements using all available media;

Specific notifications for all major sources to follow EMERGENCY action plans;

Strategy:

Warning to susceptible individuals;

People asked to eliminate all unnecessary use of electricity;

Appeals to public, plus enforcement where feasible against nonessential driving;

Businesses closed;

A11 industry shut down according to plans;

Through traffic routed onto alternate routes around city;

Police authorized to arrest any motorist driving vehicle emitting visible exhaust;

Airport: Flights restricted;

EMERGENCY plans implemented so that essential services are maintained. 
concerning activities that may or may not be essential. Those jobs must continue to be performed so that (1) essential services are maintained, (2) equipment will not cause accidents, and (3) police and fire protection, water and sewage systems, and the appropriate level of public transportation service are all ensured to function. All this requires planning. Some may even require legal enabling action. There will be little time for planning when the episode is in progress, and no chance for practice, exercises or evaluations.

Advance planning therefore includes development of detailed strategies, regulations that enable officials to call for action to be taken and to require compliance, trained personnel and equipment for surveillance and enforcement, a communications manual, and practice exercises to acquaint organizations and personnel with their tasks and to identify potential problems. 


\subsection{CITIZEN ALERT}

Actual experience with air poilution episodes in a number of cities reveals that conditions rarely, if ever, develop the way the plan anticipates. More often than not, air pollution becomes visible and perhaps evident to the nostrils but the levels reported by monitors are not high enough to call for an ALERT. Sometimes marginal air quality is accompanied by a forecast of clearing weather, which makes it unrealistic to call an ALERT. In fact, control officials may find themselves in the awkward position of knowing that regional air quality is poor, but being constrained from taking action because the ALERT criteria are not met. These criteria designed in advance, subject of public hearings and legislative review, carry the force of law, and officials generally have no authority to act outside of them.

For these reasons it is desirable to have a strategy available that can provide some relief in a marginal situation, can enable officials to act instead of sitting on the sidelines, and can give the citizen the opportunity to do something himself to reduce air pollution.

The CITIZEN'S ALERT is designed for use in marginal situations. There can be no demands and no enforcement. However, with informative, carefuily prepared announcements, an appeal can be made to the community for cooperation. No vital community services are affected. The appeal is to individuals to avoid or defer those actions that involve driving their cars. In many cases these actions are nonessential or are for convenience, and could easily be postponed.

Such actions are outlined in Exhibit 4.5. They are not hard for people to do. An informed citizenry would cooperate willingly. Citizens become informed by the determined efforts of control officials 
Exhibit 4.5

MOBILE SOURCE EPISODE CONTROL STRATEGY

\section{CITIZEN ALERT}

General Community-wide Request via Radio and TV

Do Not Use Car If Not Necessary

Carpool or Use Public Transportation

Avoid Rush Hour Driving

No Unattended Idling: Minimize Idling

Avoid Downtown Area

Report Smoky Cars to Police (Police Could Issue Warning Only)

Don't Waste Power (Electricity or Heat)

Don't Burn Refuse

Don't Use Fireplace or Barbecue 
well in advance of the episode. Newspaper articles, community. speeches, news briefs, pamphlets, school notices, etc.--any number of methods are available. Even if the actual reducation in total emissions is small, the importance of planned, participatory action being taken can well be appreciated. 
4.6 Timing of Alert Declarations

The timing of alert declarations and cooperation of agencies,..' media and citizens are crucial to the success of a motor vehicle episode control strategy. An attempt has been made to illustrate the time sequence.

Figure 5 is a pictorial representation of a two-day period: On the first day poor atmospheric dispersion conditions begin to affect the urban area, and an Air Stagnation Advisory is issued by the National Weather Service or the local EMSU. The actions required by the control agency are indicated. On the second day, the vehicle control strategy is in effect. Depending on conditions, the third day could see an ALL CLEAR, a continuation of the ALERT STRATEGY, or the declaration of an EMERGENCY, which would call for the closing down of much of the normal activity in the region.

The situation during an EMERGENCY would be much like that of a Sunday or a holiday, except that citizens would refrain from activities that would require the use of automobiles; they would avoid outdoor exercise and would keep to a minimum their use of energy and community services .

If real cooperation is to be obtained without unnecessary disruption and at a minimum, of economic loss, careful timing is essential. Ideally, the sequence would follow Fig.5. The basis for this timing is to announce the alert before people leave their place of work in the afternoon. This allows time for people to plan carpools, stagger work hours, or arrange for absences, if necessary.

Working back in time, the control agency must declare the alert in time to contact the media (and hopefully the afternoon newspapers). 

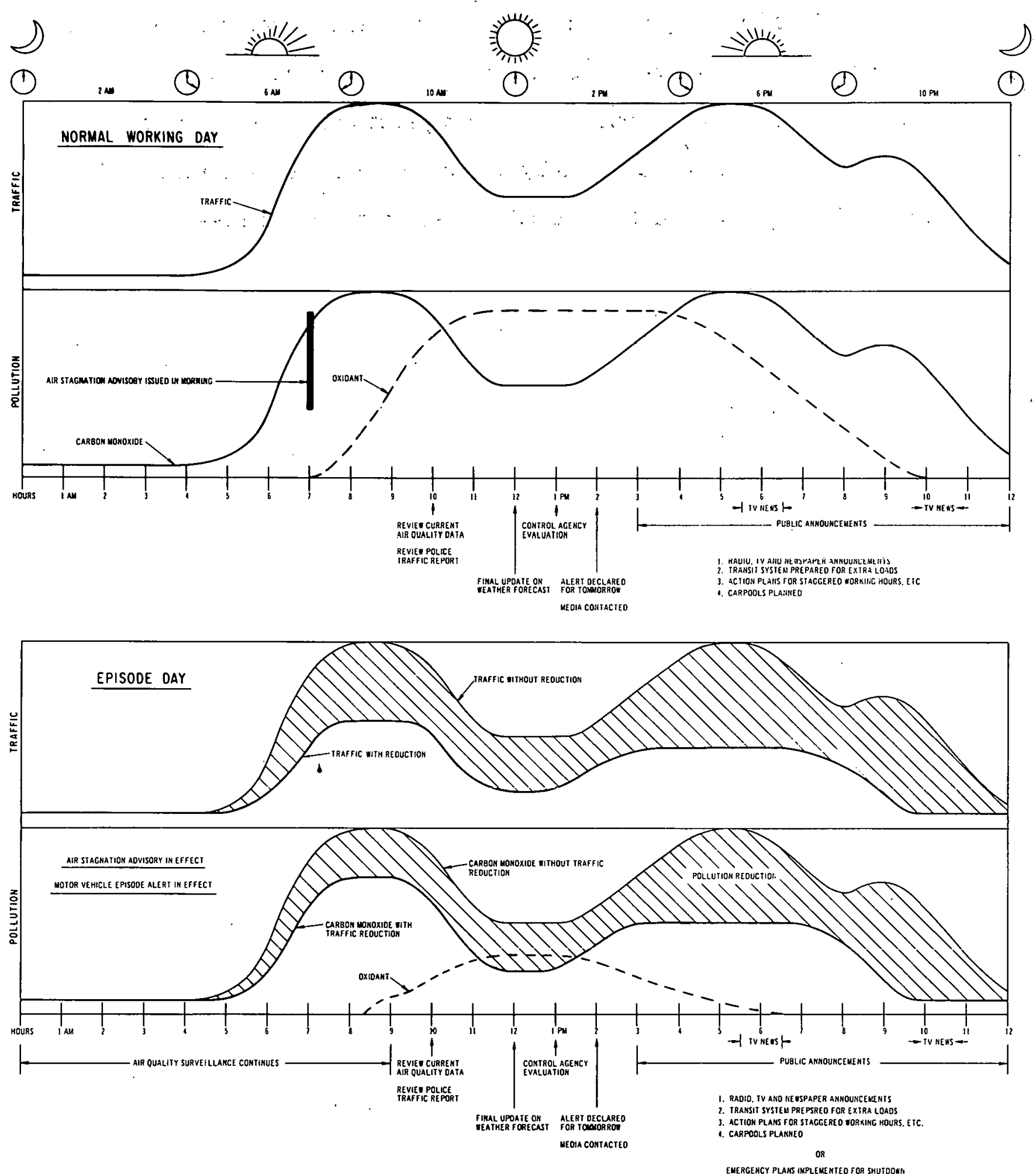

Fig. 5. Timing of Alerts 
In the example of Fig. 5, a final update on the weather forecast is called for at noon. At 10 AM reports are obtained of air quality data and traffic data are obtained from the police department. Then the agency can make its evaluation and determine whether or not a declaration need be made. The flowsheet of Exhibit 4.1 illustrates this process. 


\subsection{Criteria for Alert Stages}

It is absolutely essential that the criteria for declaring alerts be clearly stated and recorded. In many states the criteria will be a formal part of the episode control regulations and therefore carry the force of law. The criteria should be fully understood by the people who have to make the evaluation of conditions and determine whether or not an alert should be declared. Ideally, the criteria should also be understood by the pubiic. This takes a substantial effort, but it has important benefits from the operational standpoint.

When air pollution levels do build up, the public expects action to be taken. Therefore it is valuable if the public, the newspapers, the weather reporters on radio and television, etc., know that criteria do exist. Then they can appreciate the seriousness of the situation and understand the actions taken by the control agency.

The WATCH or FORECAST stage is extremely important, not only because it gives time for the agency to organize itself and other agencies, but also because with the WATCH in effect ALERTS can be declared if specified pollutant levels are reached. WATCH criteria are presented in Exhibit 5.1.

Because of the unique characteristics of the mobile source poilutants, it is logical to develop different sets of criteria for CO and for photochemical oxidants. A possible approach to CO criteria is indicated in Exhibit 5.2. Another approach that involves a projection of possible $\mathrm{COHb}$ buildup in exposed persons was published by Rossin and Roberts (15).

Exhibit 5.3 is for photochemical oxidant. Although the mechanisms involved are not entirely understood to the point where accurate predictions can be made from one day to the next, the method calls for 
a prediction of the conditions for the following day. The success of this approach depends heavily on the data base available for the region and the capabilities, experience and judgment of the meteorologists in the local region.

The criteria for declaring an EMERGENCY are outlined in Exhibit 5.4. The strategy for the EMERGENCY stage involves regionwide shutdowns, so the criteria have to be applied with the entire region in mind, even though high readings from a single monitor are all that are required to meet the criteria. 
Exhibit 5.1

MÓBILE SOURCE EPISODE CONTROL

WATCH CRITERIA

A WATCH can be declared on the basis of any one of several criteria being met:

1. ASA issued by U.S. Weather Service or local EMSU.

2. Local or regional stagnation advisory or extended inversion forecast issued by U.S. Weather Service or local EMSU, after evaluation by agency.

3. On basis of available weather forecasts, State EPA, . city agency, county agency, or any official air pollution control agency can declare a WATCH within its jurisdiction.

4. Air quality levels at any monitor exceed the WATCH* criteria, unless there is a forecast of substantiaily increased ventilation within the next six hours.

Regardless of which agency declares the WATCH, the contacts specified in the Communications Manual must be made promptly.

When an agency declares a WATCH, all other agencies within its jurisdiction (and in the region covered by the WATCH) also go on WATCH status as soon as they are notified of its declaration.

*If WATCH concentration criteria have been established: 
Exhibit 5.2

EVALUATION FOR MOBILE SOURCE EPISODE CONTROL

ALERT CRITERIA FOR CARBON MONOXIDE

Concentration:

$30 \mathrm{ppm}$

$50 \mathrm{ppm}$ $3 \mathrm{hr}$. average
any reading

Distribution of monitor readings:

\section{Forecast:}

ASA in effect

or criteria such as those in Ref. (16)

Day of Week coming up:

Workday

Saturday

Sunday

Holiday

Time of Day:

Decision between noon and 2 PM required to implement strategy for next day, and to appeal for evening rush hour control.

Exposure:

Characteristics of monitor locations that relate monitor readings to levels breathed by people.

Effective exposure time.

Maximum possible exposure time for populations.

Effective $\mathrm{COHb}$ exposure potential.

\section{Traffic:}

Characteristics of traffic patterns that could have special influence on monitor response. 
Exhibit 5.3

EVALUATION PLAN FOR MOBILE SOURCE EPISODE CONTROL

ALERT CRITERIA FOR PHOTOCHEMICAL OXIDANT

Concentration:

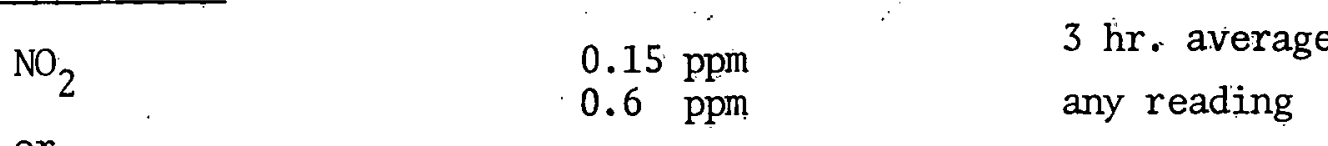

Or $\quad 0.08 \mathrm{ppm}: \therefore$ any reading

Sufficient hydrocarbons are assumed to be present regardless of monitor data.

Forecast:

ASA

or Local forecast of poor dispersion

and Sunshine forecast (no substantial overcast)

Consider season and temperature.

Day of Week Coining Up:

Workday

Saturday

Sunday

Holiday

Time of Day:

Decision between Noon and 2 PM required to implement strategy for next day.

Appeal can be made to avoid nonessential driving during evening rush hour. 
Exhibit 5.4

MOBILE SOURCE EPISODE CONTROL

EMERGENCY CRITERIA

Regional Air Pollution FMERGENCY in effect based on other pollutants plus forecast.

or:

EMERGENCY declared for next day if:

1. ALERT in effect:

and forecast for next day shows continued inadequate ventilation

2. Levels reached at any monitor by noon:

$\begin{array}{llc}\mathrm{CO} & 30 \mathrm{ppm} & 8-\mathrm{hr} . \text { average } \\ \mathrm{NO}_{2} & 0.3 \mathrm{ppm} & 24-\mathrm{hr} . \text { average } \\ \text { Oxidant } & 0.3 \mathrm{ppm} & 1-\mathrm{hr} . \text { average }\end{array}$

3. Analysis of pollution levels shows that effective exposure to population is equivalent to levels set. in 2 (above). 
6.0 Communications

6.1 Communications Plan

An effective and workable commuications plan is essential to any episode control program. Careful preparation is particularly critical when a key element of the program requires cooperation on the part of the public at large. This discussion applies to episode control programs in general, not just for mobile source control. A basic discussion can be found in Ref. 16. The communications plan must cover four different avenues:

1. Internal (within the control agency) -

Data pertaining to air quality, weather conditions, forecasts, resources available, and traffic or other local conditions must reach all persons with responsibilities relating to the strategy. Once decisions are made, declaration sheets are prepared and posted to avoid misinformation. A status board and wall maps can be valuable tools. (The communications plan does not usually cover the routine gathering of data from air monitoring stations or receipt of daily weather forecasts. These are part of standard operating procedures.)

2. External (governmental and administrative) -

There will be a set of agencies - Federal, State, regional, municipal, etc." - that have to be notified of the status of developments and of any decisions or actions taken. Other cooperating air pollution control agencies have to be contacted to obtain additional air quality information and to pass to them data available at the control agency. 
A plan can be developed through which the control agency need make only one call to each jurisdiction; subsidiary plans then require the party.called to pass information to predetermined offices within his jurisdiction. Special calls may be necessary to handle mobile source strategies, such as calls to the traffic police department and to the metropolitan mass transit authorities.

3. Institutional and Nongovernmental Depending on conditions and on applicable episode regulations, notifications may have to be transmitted to public utilities, school systems, hospitals, major industrial pollutant sources, news services and citizens' organizations.

4. The General Public Any episode strategy requires public cooperation, public understanding, and in some cases, public participation. This is particularly true for the mobile source control strategies discussed in this report. Reaching the public requires timely transmission of concise, well-planned information packages to the newspapers, radio stations and television stations. In most large metropolitan areas there is a central. news service that disseminates news releases hy wire to ail the media. In order for these efforts to be truly effective, the agency must be aware of deadline times for newspaper editions and widely viewed telecasts, and meet these deadlines. when alerts are to be announced. 
Planning is clearly the essential element of the communications element. A good plan will include a communications manual (Sec. 6.2) that lists the contacts to be made in a convenient format. It clarifies and documents the obligations of the agency and all others involved in carrying out an effective episode control effort.

Equally important, however, is understanding: We speak of public understanding and its importance to episode control, but this is only a part of the challenge. It would be highly desirable to develop an understanding of the episode problem and control strategy with the persons who transmit news and information: the radio and TV news reporters, the weather reporters and the environmental writers. "The same type of understanding should be sought among public officials and managers of major institutions and industries in the region. This subject is touched upon in Sec. 6.3.

\subsection{Communications Manual}

The Communications Manual includes references to all communications required during the progress of an air pollution episode. It is also a suitable document for presenting sample copies of declaration sheets for all episode stages, sheets that record information to make sure that an adequate log-book record of events is maintained, and checklists that are filled out by agency personnel to document the fact that calls have been made. Copies of each of these sheets are stored in the control center for use as required. The various items in the Manual are outlined below.

\subsubsection{Directory}

The Manual contains a Directory.listing all the agencies, institutions and persons that are likely to be contacted, complete. 
with addresses and telephone numbers. Some of these will be repeated on communications checklists, but experience has shown that the Directory itself will save a lot of time and confusion.

The Directory will include (among others):

- Air pollution control agencies and departments of all political jurisdictions in the region. (cities, counties, etc.)

- State, Federal and Regional Offices

- Pollution Control Board Offices

- Offices of National Weather Service, CAMP Station, EOCC, EMSU, numbers on which recorded air quality or weather.forecasts are obtained.

- Public health officials

- School system officials

- Offices of Mayors; Governors, etc.

- Press secretaries for the above

- News media, including newspapers, radio, TV, news services, etc.

- Public utility company dispatchers

- Police Dept., Fire Dept., Dept. of Streets, State Highway Police, Sheriff

- Public Transit Authority

- Airport, railroads

\subsubsection{Episode Potential Information Sheet}

Every time a monitoring station gives a reading in excess of an alert criterion, or any time an Air Stagnation Advisory is received, data should be entered in a permanent record log book and also be displayed 
in the Control Center. The "Episode Potential Information Sheet", like the one in Exhibit 6.1, should have blanks for recording station location, time, pollutant and concentration. These sheets are particularly useful for agencies other than the central control agency.

Each jurisdiction has copies of these sheets, with their own letterheads and with blanks designed to fit their monitoring system. A space is provided to initial the time that the data were reported to the central control agency. If a WATCH is declared, the Episode Potential Infornation Sheet is filed, and further data continue to be recorded in a routine fashion.

\subsubsection{Declaration Sheets}

For each stage of the Episode Control Plan there is a "Declaration Sheet". (See Exhibit 6.2 for an example of a WATCH' Deçlaration Sheet.) The sheet is filled out by the Control Center staff or the Episode Control Task Force." When an episode stage is declared, a Declaration Statement is prepared and recorded on the Declaration Sheet. This Declaration Statement includes concise information on the air quality, the region affected, and the meteorological forecast. It states the Agency that declared the alert stage, the time and the name of the responsible official.

The Declaration Statement contains the basic information to be communicated to each of the contacts listed on the Communications Checklists. When the statement has been made available to persons responsible. for making calls and contacts, the sheet is posted in the Control Center on the status board. This provides an easily accessible status report to staff and visitors. 
Exhibit 6.1

\section{(Jurisdiction)}

\section{Episode Potential Information Sheet}

Record any monitoring data that exceed the Alert values. Report values by telephone to the Control Center. Record the time of the call in the "Reported" column.

Air Quality Data

Date

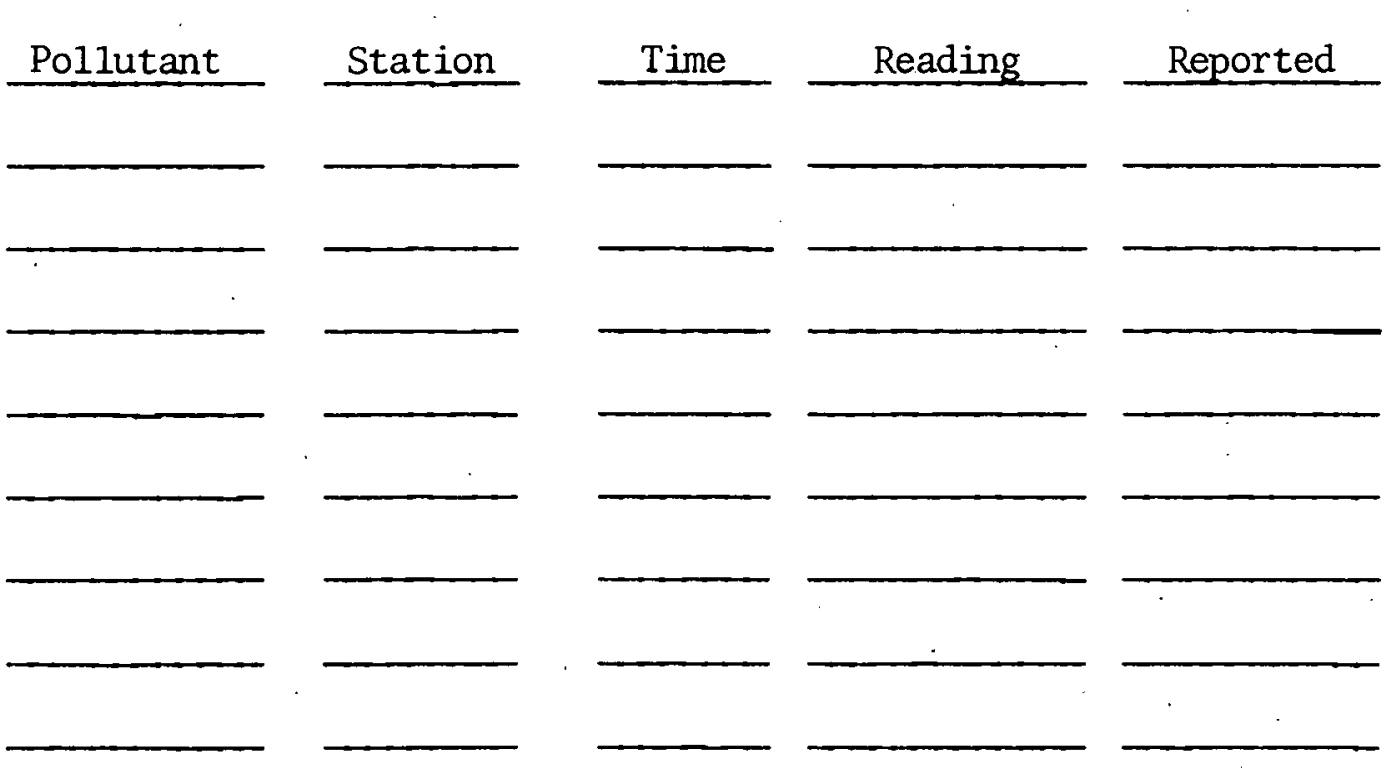

Control Center ............ (Telephone No.)

Neighboring Jurisdictions.....

Notes on further actions:

File this sheet in Log Book 


\section{Exhibit 6.2}

\section{WATCH Declaration Sheet}

Forecast Received

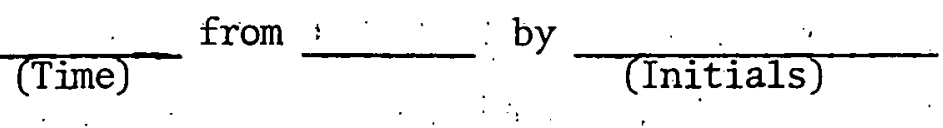

Summary of Forecast:

Air Quality Data:

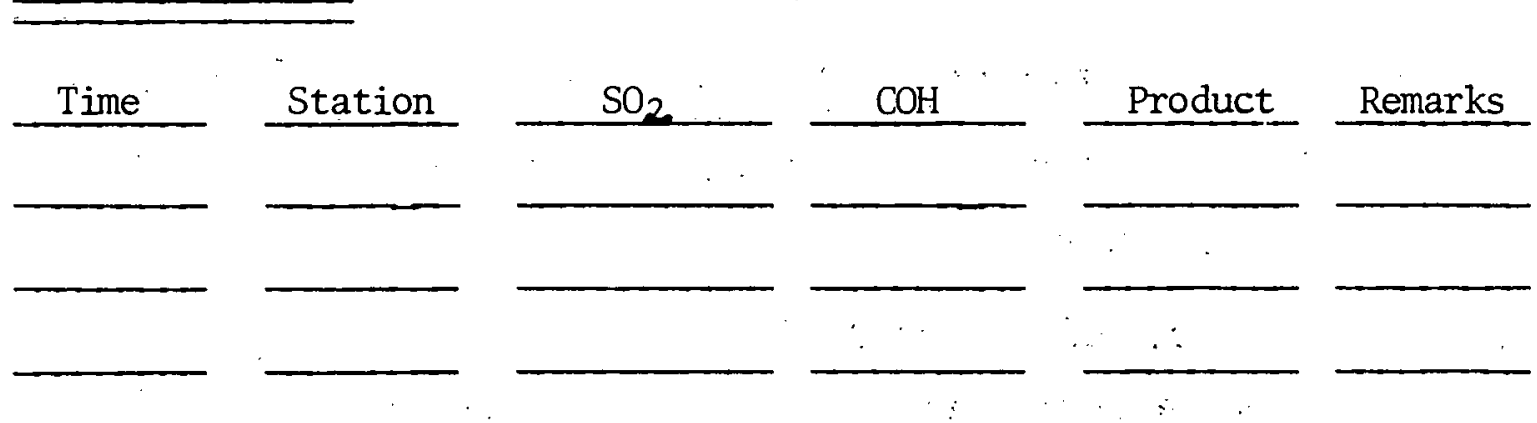

WATCH Declared:

by: (Responsible Official)

WATCH Declaration Statement (to include air quality, region affected and forecast):

Press release will follow.

Recorded telephone message updated:

(Time)

Post this sheet on Control Center Status Board

ALL CLEAR or ALERT Declared: Date Time

File this sheet in the Episode Logbook 
The Declaration Statement is read over the telephone to the City News Bureau or the news desks at various news media. This fulfills the legal obligation of the Control Agency to inform the public via the news media. However, additional information should be supplied to the media. A press release is prepared and sent by messenger to the news bureau or other predetermined recipients. Depending on the circumstances, it may be appropriate to hold a press briefing or press conference, or hold interviews for various media representatives.

When a higher alert stage or an All Clear is declared; the final entry is made on the current Declaration Sheet. It is then removed from display and filed in the Episode Logbook; the new Declaration Sheet is posted in its place.

\subsubsection{Communications Checklists}

For each episode stage there is a Communications Checklist. Each contact on the Checklist must be contacted from the Control Center, and must be notified of the situation by reading the Declaration Statement. An example appears in Exhibit 6.3.

The person making the contact indicates the time of the call on the Checklist and enters his initials next to it.

Depending on the conditions and the region affected, other contacts may be appropriate. The telephone numbers for these additional contacts are found in the Directory. Other contacts made are recorded at the bottom of the sheet or on attached sheets.

When the contacts have been completed, the Checklist is filed in the Episode Logbook. 
Exhibit 6.3

Communications Checklist

\section{Air Pollution Episode ALERT Notifications}

ALERT Declared: Time

Date

The following contacts must be made from the Control Center to communicate the ALERT Declaration Statement:

Telephone Number

Director, State EPA

Director, City Dept. of

Environmental Contro1

Director, County Dept. of Environmental Contró1

USEPA Regional Office'

Office of Mayor

Health Dept.

Electric Utility Co. Dispatcher

Gas Co. - Dispatcher

City News Bureau

Police Dept.

Regional Transit Authority

Superintendent of Schools

Other$$
\text { - }
$$

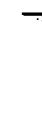
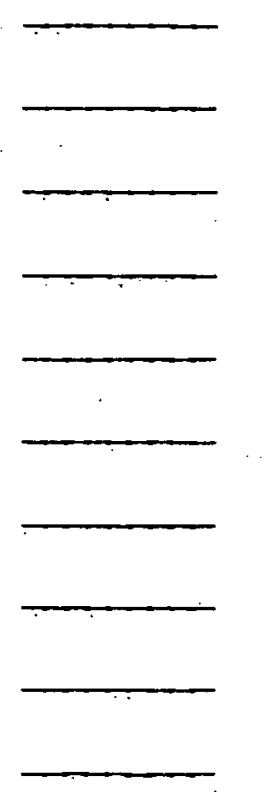

Called By

(Initiais) Time

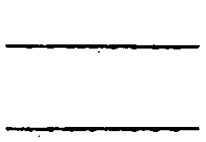




\subsubsection{Episode Logbook}

All of the Declaration Sheets and Checklists form a part of the permanent record of the Control Center. They are the objective evidence of actions taken during the episode.

The Episode Logbook is kept by the Control Agency. Entries are made whenever high pollutant levels are reported or whenever a forecast is received that suggests the meteorological potential for episode conditions. Whenever a WATCH is declared, the Episode Logbook becomes a full-time $\log$, and all actions and developments are noted in i.t.

After the episode is over and after all the sheets have been put into the Episode Logbook, it can serve as the primary source for analysis of the episode and for evaluation of the effectiveness of control actions.

\subsubsection{Confirmation}

A perennial problem for public officials in general, and pollution control agencies in particular, is the threat of false alarms. False alert information could be circulated by pranksters or by persons with deliberate intention of causing disruption and embarrassment. It is prudent to have built into the communications system a check to minimize this danger. The particular method used will depend on the needs and resources of the agency, and on its concern for the potential problem.

In theory it would be fine if the individuals called were acquainted with the Agency dispatchers. Thus voices would be recognized and trust easily established. However, this breaks down during busy periods; people are replaced by their alternates, etc.

A foolproof system would require each call to be returned. When the recipient calls the Control Agency he confirms the validity of the alert. 
$\therefore \quad$ Some agencies use a recorded telephone message to inform the public. The recipient could simply call the recorded message phone number to verify the alert declaration. If news media are carefully warned to doublecheck any telephone call regarding episode control with the Agency or a recorded message, there is a good chance that.false reports will not appear as headlines.

\subsection{Public Information and Public Understanding}

The effectiveness of episode control strategy, particularly for control of mobile sources, depends on getting information to the public. The importance of clear, concise press releases, developed in advance, has been discussed above. The section that follows presents some sample press releases.

Episode control is not a subject that is high in the public mind from day to day. On the other hand, the public will make its evaluation of the Control Agency's performance on what they see when and if an episode develops.

The media form the bridge between the Agency and the public. Experience has shown that misunderstandings often occur between control agencies and the media with respect to what the agency should do, or for that matter, has authority to do. Perhaps the biggest problem centers around the question of how serious an episode situation actually is. Serinısness depends on quantitative measures. Even expressed by comparison with established standards, the dangers to health are seldom obvious nor straightforward.

It is too much to hope that large segments of the general public will bother to study quantitative standards or actual data. The best hope is for understanding on the part of the reporters who handle the 
news. These may be local environmental reporters, radio and TV weathermen, local public interest and city desk reporters and editorial writers. Communications experts suggest the importance of personal contacts, carefully prepared press releases in plain English, briefing sessions, and full information to assure continuing credibility.

Ideally, a public understanding effort should be developed on a community-wide basis. This requires time, effort, money and creativity. It can involve the media, citizens' organizations, schools, hospitals, professional societies, etc. It must be a professional job. The interested public should be made aware that episode plans exist, when they will be used, what is supposed to happen, and what the individual citizen can do.

Citizens' organizations can be extremely helpful in improving public understanding. During an episode, citizen group spokesmen often are contacted for interviews. They should be well informed and not feel left out with regard to factual information. Some citizens' groups have an active role to play in certain regions' episode programs. Such participation has to be carefully planned. No agency can transfer its legal or professional responsibilities to volunteer groups, nor should they depend on making contacts to persons who have responsibilities elsewhere. The businessman or housewife volunteer cannot be expected to be on call at all times. However, there are avenues for citizen participation, particularly in development of better public understanding and in observation and critical review of the performance of governmental agencies and public officials. 


\subsection{Sample Press Releases}

The sample press releases that follow are not specific to any region. Titles, department names, state and municipal agency names and responsibilities will vary extensively. They are just offered as an indication of what can be done. The following sample press releases are offered:

Exhibit 6.4 WATCH

Exhibit 6.5 CO ALERT

Exhibit 6.6 SMOG ALERT

Exhibit 6.7 EMERGENCY

'Exhibit 6.8 CITIZENS' ALERT

Exhibit 6.9 ALL CLEAR 
Exhibit 6.4 WATCH

Sample Press Release

Date

Time

\section{FOR IMMEDIATE RELEASE}

This afternoon, Dr. William Blank, Director of the State Air Pollution Control Bureau, declared an air pollution WATCH.

Dr. Blank announced that the National Weather Service had issued. an Air Stagnation Advisory at 2:30 PM effective for the next 24 hours.

"That advisory requires us to declare a Watch,:" Blank explained. "The NWS promised another bulletin this evening."

The Watch puts the Bureau on round-the-clock operations. Similar action is being taken by the air pollution control departments in North County, East County and Metropolis.

In Metropolis, Mr. J. H. Clear, Manager of Environmental Control, stated that none of the air pollution monitors had reached alert levels.

"But we're watching the data closely," he said. "If the carbon monoxide or smog alert levels are exceeded for four hours and we still have a stagnation in effect, we'11 declare an Alert in Metropolis.

'We' 11 review the situation in the morning, and if it looks like this stagnation is going to continue, we'11 have an Alert. Then people will be expected to take public transportation or carpools, postpone car trips, and just not use their cars unless they have to."

The Department hopes that this action will keep pollutant levels down. However, if episode criteria are exceeded for two days and the 
stagnation does not break up, the Department could declare an Emergency.

"We don't expect it, but we have pians to take the required action before air pollution can become a threat to the health of the public," Mr. Clear stated. 
Exhibit 6.5 CARBON MONOXIDE ALERT

\section{Sample Press Release}

Date

Time

FOR IMMEDIATE RELEASE

The Department of Environmental Control has declared an air pollution ALERT.

"The carbon monoxide levels exceeded $30 \mathrm{ppm}$ (the State episode standard) for four hours at the Central Expressway Station", Commissioner C. T. James announced.

"We have a Watch in effect and we don't expect this stagnation condition to break by tomorrow morning. This means that all air pollution levels are above normal."

The Commissioner stated that the Alert requires cooperation by everyone. Citizens are asked to take public transportation, use carpools, and not to drive unless absolutely necessary. He suggested that any nonessential trips be postponed. The Metropolitan Transit Authority has promised to have all of its available vehicles ready to meet an unusually high demand tomorrow.

While the Alert is in effect, police will ticket any unattended cars left idling, and warn any drivers that leave engines running while parked.

The Health Commissioner, Dr. Philip Pill, warns that persons susceptible to heart, throat or lung diseases remain indoors and avoid unnecessary activity. He pointed out that carbon monoxide effects of an episode are temporary. "A person could become a bit drowsy or slower 
to react while driving," he stated.

The Department of Environmental Control will review the situation tomorrow morning with other key State and local officials. If the stagnation does not clear, the Alert may have to be extended another day.

If pollutant levels rise to the Emergency levels, it may be necessary to call for a regionwide shutdown of industrial and all other activities. "This would eliminate much of the driving as a consequence," said the Commissioner. 
Exhibit 6.6 SMOG ALERT

Sample Press Release

Date

Time

FOR IMMEDIATE RELEASE

Today was a smoggy day in Metropolis. Tomorrow could be worse. . At a meeting of city, State, and pollution control agency officials this noon a decision was reached to declare a Smog Alert for tomorrow.

Every person is asked to voluntarily avoid any or all use of automobiles. Persons are urged to take public transportation or use carpools to go to work.

Commissioner James issued a public request that all non-essential auto use be postponed until the stagnation clears.

"Stay home, indoors," the Commissioner urged, "particularly if you may have heart or lung problems or if your eyes and nose are subject to allergic reactions."

The Commissioner pointed out that major industries are implementing their episode action plans for air pollution alerts. These are on file with the Department, and call for specific cutbacks in emissions.

"But as far as driving is concerned," he emphasized, "our success depends on how well citizens cooperate."

The Smog Alert was declared because the concentration of photochemical oxidant in the air reached $0.08 \mathrm{ppm}$ at the Central Monitoring station this morning at $11 \mathrm{AM}$. The levels are dropping this afternoon, but are liable to be up again tomorrow. 
The National Weather Service predicts another day of almost no wind but with plenty of sunshine. As a result, the emissions from automobiles react to form the now-familiar smog layer. Another meeting will be held tomorrow morning to decide on the need for Alert or Emergency action on Thursday. 
Exhibit 6.7 EMERGENCY

Sample Press Release

Date

Tịme

FOR IMMEDIATE RELEASE

- The actions taken by State and city officials have reduced the amount of pollution being put into the air by industry and autos.

However, the weather situation has been unprecedented. The city lies in a mass of trapped, stagnant air. Pollutant levels have not receded, and no fresh breeze has come in to break things up.

Tomorrow looks no better. Therefore, at 2 PM the Mayor and the Governor announced an Air Pollution Emergency for tomorrow.

The Emergency regulations require that all businesses, factories, schools, shops and offices be closed tomorrow.

"Our regulations are clear," said Governor Davis. "The conditions are approaching a threat to the health of the public. When the Alert strategy has been in effect and things fail to clear up, we cannot take further chances. The law requires that the city be shut down. Even if we did not do it, the Federal government would be required to step in and do the same thing."

All industries will comply with their Emergency Episode Plans. Employees not involved in Emergency actions are not to go to work. People with heart or respiratory problems are advised to stay indoors and quiet.

The Department of Environmental Control will issue bulletins every four hours while the Emergency is in effect. 
Exhibit 6.8, CITIZENS! ALERT

$\therefore$ Sample. Press Release

Date

Time

FOR', IMMEDIATE RELEASE

"There is an Air Pollution Watch in effect;" said Commissioner Clear, of the Metropolis Dept. of Environmental Control, "but no pollutants have reached Alert concentrations."

The Commissioner said that his technical staff does not expect dangerous pollutant levels. However, he pointed out that levels will be above normal while the stagnation lasts.

"We have no legal authority to act unless an Alert is declared," Clear stated. "People ask what they can do to help." While this stagnation holds; people can voluntarily avoid driving their cars. They can take public transportation to work, or at least ride in carpools. If the trip can wait, put it off. Don't leave engines idling. 'In' fact, don't leave electric lights on at home unless they're'needed."

The Commissioner said that the situation would be evaluated continually and another bulletin would be issued this evening. 
Exhibit 6.9 ALL CLEAR

Sample Press Release

Date

Time

\section{FOR IMMEDIATE RELEASE}

The National Weather Service forecasts that a cool front, with showers and gusty winds, will pass through the Metropolis area this afternoon. Therefore, it has lifted its Air Stagnation Advisory after 3 PM . today.

Meanwhile, however, the Episode Control Alert plans will remain in effect.

No episode conditions are expected tomorrow. Industries may prepare to go back into full operation after the All Clear is issued. 'Ihe Department of Environmental Control and the State will announce the: "All Clear" on radio and television.

The passing frontal weather system is expected to clear the air and end this period of episode control action. 


\section{ACKNNOWLEDGMENTS}

This work was carried out as part of a project supported by the Emergency Operations Control Center (EOCC), Office of Air Programs, UṠEPA. The author thanks Darry1 D. Tyler, Chief, and Charles W. Whitmore, Asst. Chief, EOCC, for their interest in this phase of episode control strategy development. However, while no claim is made for their total originality, the concepts and approach presented in this report are those of the author. They do not necessarily reflect the position of the EOCC and in no way do they constitute a statement of policy by the USEPA.

The author is also indebted to Vaun Newill, M.D., and John Knelsen, M.D.; USEPA, and Rodney R. Beard, M.D., School of Medicine, Stanford University, for their helpful discussions of research on the clinical effects of various poilutants on human beings. 


\section{REFERENCES}

1. "Air Quality Criteria for Carbon Monoxide", National Air Pollution Control Administration, Publication No. AP-62, March 1970.

2. "Air Quality Criteria for Oxides of Nitrogen", National Air Pollution Contro1 Administration, Publication No. AP-84, 1971.

3. "Air Quality Criteria for Hydrocarbons", National Air Pollution Control Administration, Publication No. AP-64, March 1970.

4. "Air Quality Criteria for Photochemical Oxidants", National Air Pollution Control Administration, Publication No. AP-63; March 1970.

5. Shy, C. M., Creason, J. P., Pearlman. M. E., McClain, K. E. Benson, F. B., and Young, M. M., Journal Air Pollution Control Association 20, 539 (1970), and 20, 582 (1970).

6. Federal Register, Vol. 36; №. 84 (April 30, 1971).

7. Federal Register, Doć. 71-15593, Filed 10-22-71.

8. Ref. 1, op cit, Fig. 8-4, p. 8-10.

9. Ref. 1, op cit, Fig. 8-5, p. 8-11.

10. Barth, D. S. , Romanovsky, J. C., Knelson, J. H., Altshuller, A. P., and Horton, R. J. M. , Office of Research and Monitoring, U.S. E.P.A. , Journal Air Pollution Control Association, Vo1. 21, No. 9, Sept. 1971 (544-548).

11. Beard, R. R., and Wertheim, G. A., "Behavioral Impairment Associated with Small Doses of Carbon Monoxide", American Journal of Public Health, Vo1. 57; 2012 (November 1967).

12. "Effects of Chronic Exposure to Low Levels of Carbon Monoxide on Human Health, Behavior, and Performance", National Academy of Science, National Academy of Engineering, p. 33-35 (1969).

13. Personal: Communication, John H. Knelsen, M. D., U.S. E.P.A., Division of Health Effects Research.

14. Heuss, J. M., Nebel, G. J. and Colucci, J. M., "National Air Qualit.y Standards for Automotive Pollutants--A Critical Review", Journal Air Pollution Control Association, Vol. 21, No. 9, 535 (Sept. 1971).

15. Rossin, A. D., and Roberts, J. J., "Episode Control Streategy for Carbon Monoxide", Journal Air Pollution Control Association, Vol. 22, No. 4, 254 (April 1972).

16. Guide for Air Pollution Episode Avoidance, U.S. E.P.A., Office of Air Programs, AP- 76 (June 1971). 